\title{
A Novel Computational Approach to Combine the Optical and Thermal Modelling of Linear Fresnel Collectors using the Finite Volume Method
}

\author{
M.A. Moghimi, K.J. Craig* and J.P. Meyer \\ solarUP, Clean Energy Research Group, \\ University of Pretoria, Pretoria, South Africa +27-12-420-3515 \\ * Corresponding author: ken.craig@up.ac.za
}

\begin{abstract}
A computational approach is presented, which uses the finite volume (FV) method in the Computational Fluid Dynamics (CFD) solver ANSYS Fluent to conduct the ray tracing required to quantify the optical performance of a line concentration Concentrated Solar Power (CSP) receiver, as well as the conjugate heat transfer modelling required to estimate the thermal efficiency of such a receiver. A Linear Fresnel Collector (LFC) implementation is used to illustrate the approach. It is shown that the Discrete Ordinates method can provide an accurate solution to the Radiative Transfer Equation (RTE) if the shortcomings of its solution are resolved appropriately in the FV CFD solver. The shortcomings are due to false scattering and the socalled ray effect inherent in the FV solution. The approach is first evaluated for a 2-D test case involving oblique collimated radiation and then for a more complex 2-D LFC optical domain based on the FRESDEMO project. For the latter, results are compared with and validated against those obtained with the Monte Carlo ray tracer, SolTrace. The outcome of the FV ray tracing in the LFC optical domain is mapped as a non-uniform heat flux distribution in the 3-D cavity receiver domain and this distribution is included in the FV conjugate heat transfer CFD model as a volumetric source. The result of this latter model is the determination of the heat transferred to the heat transfer fluid running in the collector tubes, thereby providing an estimation of the overall thermal efficiency. To evaluate the effectiveness of the phased approach in terms of accuracy and computational cost, the novel 2-D:3-D phased approach is compared with results of a fully integrated, but expensive 3-D optical and thermal model. It is shown that the less expensive model provides similar results and hence a large cost saving. The novel approach also provides the benefit of working in one simulation environment, i.e. ANSYS Workbench, where optimisation studies can be carried out to maximise the performance of linear CSP reflector layout and receiver configurations.
\end{abstract}

Keywords: False scattering and ray effect, Linear Fresnel Collector, SolTrace, CFD, Nonuniform solar heat flux 


\section{Introduction}

The traditional approach to determining the thermal efficiency of linear Concentrated Solar Power (CSP) plants, whether one with parabolic trough collectors (PTC) or Linear Fresnel Collectors (LFC), is to model the solar load using a ray tracer, of which the Monte Carlo method is the most common (Bode and Gauché, 2012), and then to apply the resulting absorbed solar irradiation as a boundary condition in a Computational Fluid Dynamics (CFD) model to determine the conjugate heat transfer, which involves mechanisms like conduction, natural and forced convection, as well as thermal re-radiation. LFCs are the focus of this paper, as this technology has a number of advantages over the more established PTCs that are yet to be fully exploited through optimisation (Moghimi et al., 2014, 2015). Some of the advantages include easy maintenance, a stationary absorber or receiver (no high pressure flexible joints), a separated receiver and reflector system, lower mirror heights, cheaper mirrors, a lighter structure, a simpler tracking system and a lower cost of operation and maintenance.

Previous researchers conducted optimisation studies that included economic factors (Mertins, 2009). The use of levelised costs such as the Levelized Cost Of Electricity (LCOE) parameter aims at comparing different CSP plants (and other renewable or fossil fuel equivalents) on an equal footing because of the inclusion not only of capital cost, but also of maintenance and operation cost, financing cost, decommissioning cost, etc. and comparing these with the revenue received from generated electricity (Mertins, 2009). More specifically, the total costs of an LFC plant over its lifetime can be listed as follows (Mertins, 2009):

1. Initial investment:

Costs of primary mirrors, influenced by: number of mirrors, mirror width, mirror manufacturing, transportation, storage, mounting on structure, motor and driver equipment, control system and spacing of mirrors on structure.

$>$ Elevating costs include the cost of mounting the receiver and its installation at a specific height.

$>$ Receiver cost, influenced by: geometry configuration, cavity dimension, absorber tube dimension, coating cost, insulation around receiver and front cover glass.

> Extra initial costs: piping, infrastructure, land (ground and preparation costs), project efforts (engineering, contracting, management, licence rights), uncertainties, power plant unit (turbine, feed-water tank, preheater, condenser).

2. Operating and management costs include personnel and spare parts.

3. Capital costs include financing cost, insurance premiums, interest on investment and taxes. Other studies only focused on thermal and optical performance parameters (e.g. Morin et al., 2006; Montes et al., 2012; Bernhard et al., 2008). Only considering thermal efficiency as a parameter can lead to an LFC design with fewer mirrors but surprisingly one that has an increased LCOE over one with more mirrors (Bernhard et al., 2008). Montes et al. (2012) showed that wider mirrors with larger gaps increased the thermal efficiency but they did not consider economical factors in their study. Morin et al. (2006) illustrated that such designs would lead to increased land and material cost. 
From a simulation standpoint, whether or not economic factors are taken into account, the accuracy of determining the optical and thermal performance of an LFC installation (mirror field and receiver performance) requires a validated prediction model that is able to evaluate the complex interaction between solar irradiation, including wavelength and temperature dependency, and the heat transfer fluid (HTF). This means that the optical performance of the mirror field must be simulated accurately to determine the influence of the sun angle, sun shape, concentration ratio, blocking and shading, reflectivity and reflector errors on the absorbed radiation on the collector absorber surfaces (tubes in this case). Traditionally, ray tracers are used to calculate the optical efficiency of LFCs (e.g. Lin et al., 2013; Facão and Oliveira, 2011). The thermal performance requires a simulation model, which will incorporate the relevant heat transfer modes of solid conduction, natural and forced convection and thermal re-radiation, interacting either diffusely or specularly, depending on the surface properties in the LFC receiver. CFD is regularly used in this regard and 2-D domains can be considered if the aim is only to have an estimate of the thermal losses of an LFC cavity, i.e. if the actual heat transferred to the HTF of a specific mirror field is not the aim of the simulation (Moghimi et al., 2014, 2015). To determine the latter requires a 3-D CFD model, which includes the forced convection in the HTF pipes and its interaction with the other cavity heat transfer mechanisms.

The traditional use of different software tools for optics and thermal performance (e.g., Joseph et al. (2009)) means that a single simulation-optimisation environment where parameterised models can be fully integrated remains a challenge. The current study therefore illustrates the use of the ANSYS Workbench environment, where the geometry, meshing, CFD solution and optimisation tools (DesignXplorer) are all linked through parameters (ANSYS, 2013a) to perform both the optical and thermal evaluation of the receiver within a mirror field. If illustrated to be costeffective and accurate, the environment can then be used in optimisation studies, as conducted, e.g. in Moghimi et al. (2014, 2015). Moghimi et al. (2014, 2015) used the same package for simulating a thermal model of a multi-tube trapezoidal cavity receiver and its optimisation, but the optical modelling of the domain and inclusion of the mirror field were not considered in their optimisation.

After an introduction to the Radiative Transfer Equation (RTE) and its solution using the Discrete Ordinates (DO) method on a finite volume (FV) mesh, the accuracy of the optical simulation method is illustrated for a test case from literature ( $\mathrm{Li}, 2004$; Hachicha, 2013). The recommended settings are then applied to an implementation of an LFC receiver for the FRESDEMO (Mertins, 2009; Bernhard et al., 2008) mirror field layout to illustrate the benefit of a combined FV RTE solution and heat transfer modelling. As validation, the optical results are compared with those obtained by a SolTrace (NREL, 2014) model of the mirror field and receiver. And last but not least, a fast and novel FV sequential approach is introduced to perform the optical and thermal modelling of domain. This sequential approach is based on mapping the non-uniform solar heat flux load on the heat transfer fluid (HTF) absorber pipes as determined in the 2-D optical domain, as a volumetric heat source in the thermal domain of the 3-D cavity receiver. As proof of the efficiency of the 2-D:3-D approach (the sequential FV optical and 
thermal method), it is compared with an expensive full 3-D combined RTE and heat transfer model to show both the cost-effectiveness and accuracy of the approach. In this comparison, the relative cost saving is quantified in order to illustrate the efficacy of the proposed approach.

\section{Optical modelling by introducing DO FV as a ray tracing option}

\subsection{Overcoming D0 shortcomings in ray tracing}

The determination of the non-uniform solar heat flux distribution around the absorber tubes of an LFC cavity is one of the main purposes of the optical modelling that requires the solution of the RTE. For more information about the RTE equation refer to section 1 of the supplementary material. Many methods for solving the RTE or its general form, the Boltzman transport equation (photon radiation transport), have been developed. These include flux-limited diffusion (Levermore and Pomraning, 1981), variable Eddington factors (Minerbo, 1978), spherical harmonics (Brunner, 2,000), Implicit Monte Carlo (IMC) (Fleck and Cummings, 1971) and the $\mathrm{S}_{\mathrm{N}}$ or Discrete Ordinates (DO) method (Miller and Reed, 1977). The last two are the most wellknown approximations. The IMC yields very accurate results when simulating enough particles but can become processor and memory intensive at high ray counts. The DO method, on the other hand, is easy to implement in FV, and easy to solve especially in serial calculations. In addition, the DO method determines the solution of the RTE on the same mesh as the energy, mass and momentum conservation equations, which leads to a close coupling of surface temperature and radiative energy. This implies that the DO can be applied to complex geometries

for different participating media such as non-grey, anisotropically scattering, non-isothermal, absorbing and emitting media. Nevertheless, the DO method has two major shortcomings due to its FV nature, namely the "ray effect" and "false scattering", which affect result accuracy (Brunner, 2002; Chai and Patankar, 2006). The former is also known as "ray concentration" (Martinek and Weimer, 2013), and the latter as "numerical scattering" (Li, 2004), "numerical smearing" (Jessee and Fiveland, 1997) or "false diffusion" in CFD communities (Hachicha, 2013).

Before using DO as a ray-tracing method in a solar field, the ability of reducing these shortcoming effects must be checked. Various methods were suggested by different researchers (Li, 2004; Jessee and Fiveland, 1997; Hachicha, 2013), but their implementation in ANSYS Fluent due to its closed-source specification is almost impossible. Therefore, in the following paragraphs, the origin of these errors and their alleviation are discussed.

For implementation of the RTE as an FV method and an assurance of energy conservation, Raithby and Chui (1990) suggest that an angular discretisation with particular subdivisions (control angles) is performed over the background FV spatial discretisation (FV mesh). This means that the RTE is integrated into both control volume and control angles. The particular 


\begin{tabular}{|c|c|c|c|c|}
\hline \multicolumn{5}{|c|}{$\begin{array}{c}\text { Table 1: Number of mathematical angular discretisation } \\
\text { assumptions }\end{array}$} \\
\hline $\begin{array}{c}\text { Quadrature } \\
\text { order }\end{array}$ & $\mathbf{2}$ & $\mathbf{4}$ & $\mathbf{8}$ & $\mathbf{N}$ \\
\hline One & & & & \\
\hline Two & 2 & 4 & 8 & $\mathrm{~N}$ \\
\hline Three & 4 & 12 & 40 & $0.5 \mathrm{~N}^{2}+\mathrm{N}$ \\
\hline
\end{tabular}


angular discretisations are symmetrically chosen for any 90-degree rotation of coordinate system (Table 1 (Brunner, 2002)) and are subdivided into $N_{\theta} \times N_{\phi}$ control angles.

The DO approximation or $\mathrm{S}_{\mathrm{N}}$ method, where $\mathrm{N}$ is the number of ordinate directions, in $\mathrm{FV}$, assumes that a radiation beam is propagated in a few particular angular directions instead of being propagated in continuum angular directions (as is the case in reality or in the RTE (with its $4 \pi$ solid angle)). The latter is the source of the so-called ray effect or ray concentration errors (Brunner, 2002). This error generates a wavy solution in heat flux and can be alleviated by choosing a higher number of ordinate directions (high-order $S_{N}$ method) or by increasing the number of subdivision (control angles), i.e. minimising the solid angle extents, e.g. Kim and Lee (1989) used 14 ordinate directions $\left(\mathrm{S}_{14}\right)$ for presenting benchmark results of collimated incidence in a two-dimensional rectangular, anisotropic scattering medium. Hachicha (2013) illustrates the reduction in the ray effect by increasing the number of control angles in eight separate test cases in his $\mathrm{PhD}$ thesis.

False scattering, on the other hand, is a non-physical error that comes from the spatial discretisation. Chai et al. (1993) and Chai and Patankar (2006) reported that if the direction of radiation beam propagation was aligned with the grid lines, the numerical error which led to a smeared solution would be eliminated. However, this error can be reduced by refining the spatial grid or using more accurate spatial discretisation schemes (Hachicha, 2013).

However, due to the fact that ANSYS Fluent uses a fixed ordinates (two-ordinates- $\mathrm{S}_{2}$ ) approach, the only available options removing these errors are:

1. Increasing the control angle count,

2. Increasing the spatial mesh count, and

3. Using a higher-order spatial discretisation scheme for the DO direction equations.

The $\mathrm{S}_{2}$ in ANSYS Fluent is implemented by subdividing the angular space into $N_{\theta} \times N_{\phi}$ control angles, each of which is further subdivided by pixels. For 1-D, $2 \times N_{\theta} \times N_{\phi}$ directions of the RTE equations are solved, for 2-D, $4 \times N_{\theta} \times N_{\phi}$ directions, while for 3-D, $8 \times N_{\theta} \times N_{\phi}$ directions are computed, implying that the computational overhead and memory requirements increase linearly with each angular discretisation division and that for each spatial dimension that is added, the overhead doubles. So, to reduce the effects of these errors for the converged solution in an optical modelling simulation, in addition to a mesh study, a control angle study with higher-order spatial discretisation has to be done, before relying on the converged solution.

\subsection{Test case for oblique collimated radiation}

To illustrate the interaction between FV mesh density and the angular discretisation of the DO in reducing both the ray effect and false scattering, a test case from literature (Li, 2004) with an available Monte Carlo ray-tracing result is used.

The domain (illustrated in Figure 1) has oblique collimated radiation entering into a black square enclosure filled with a pure isotropical scattering and homogeneous medium $\left(\sigma_{s}=1, a=0\right.$ in RTE Eq.) The oblique angle is defined by $\theta=-90^{\circ}, \phi=-60^{\circ}$ and enters through a 


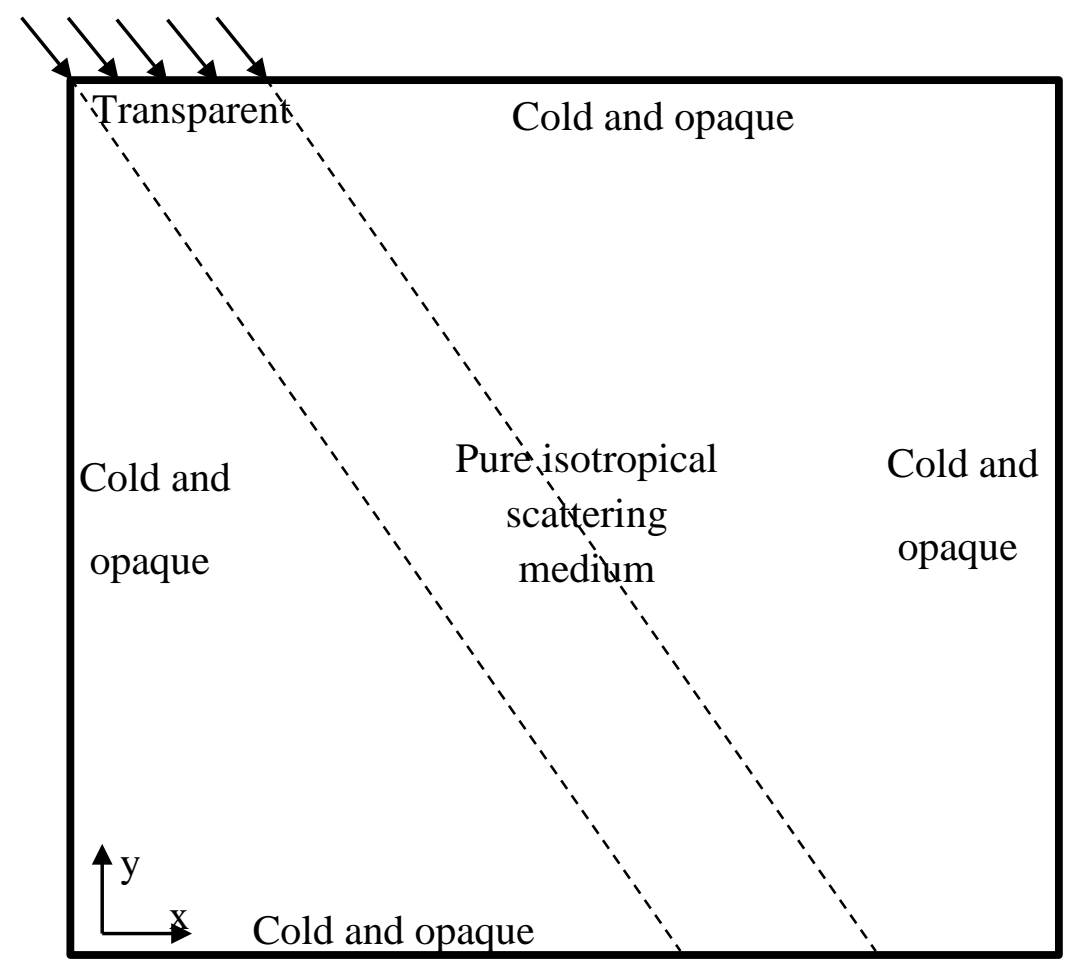

Figure1: Configuration of oblique collimated radiation case study 


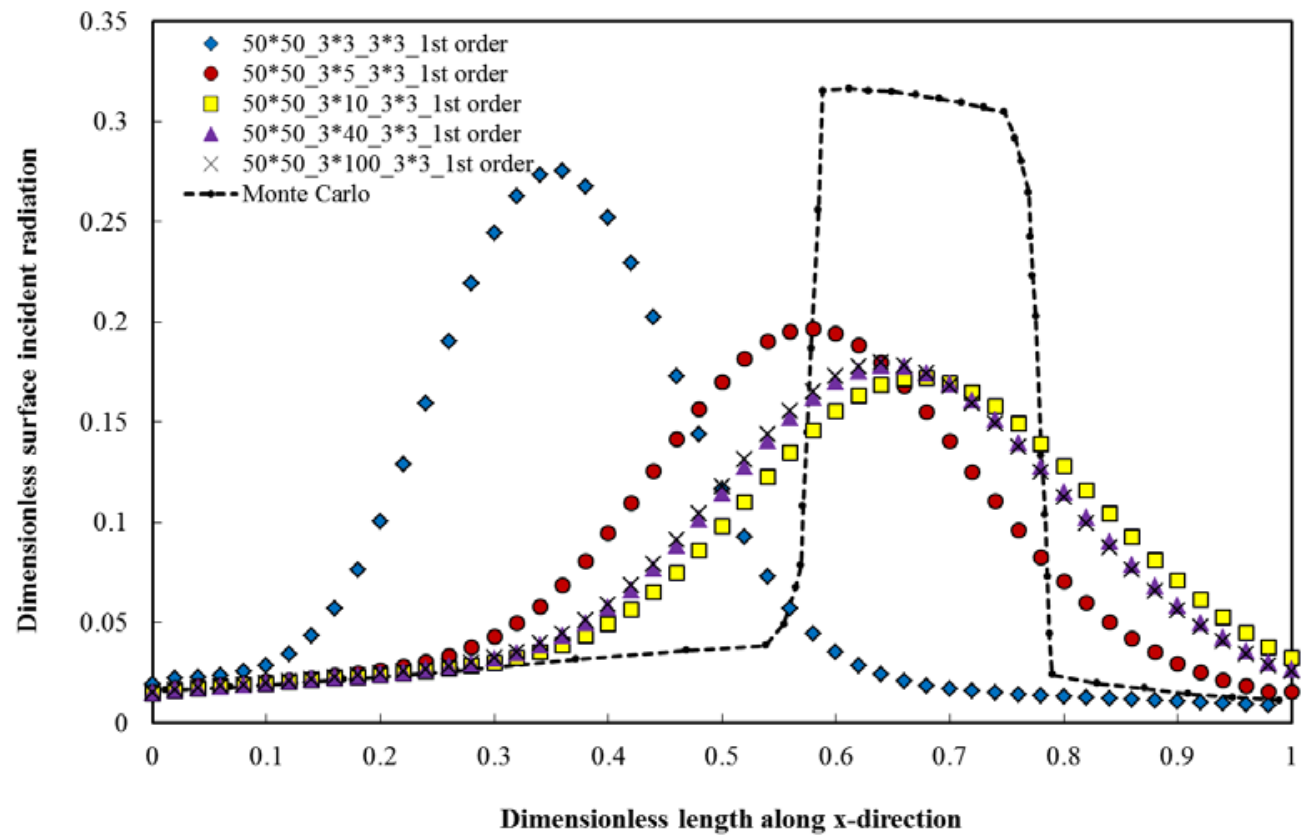

a)

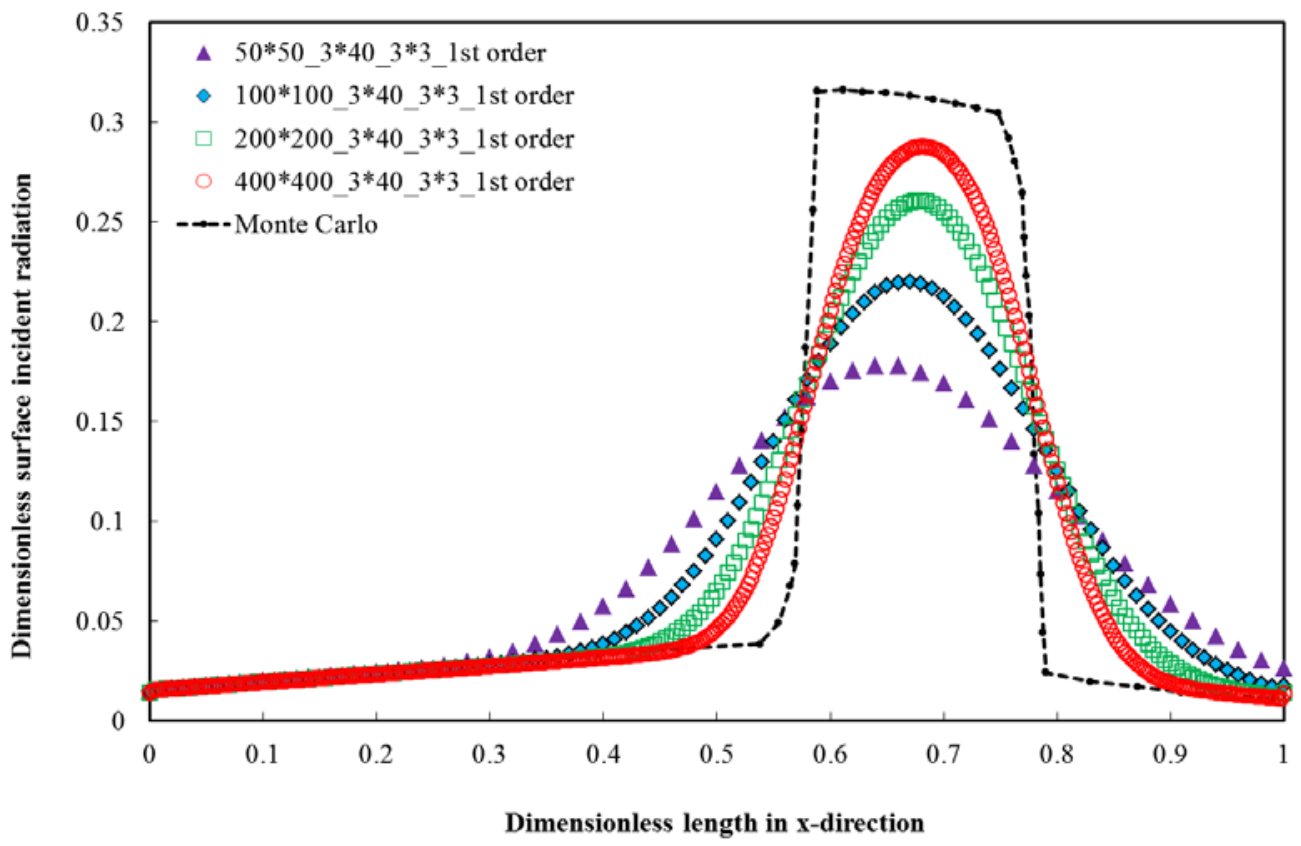

b) 


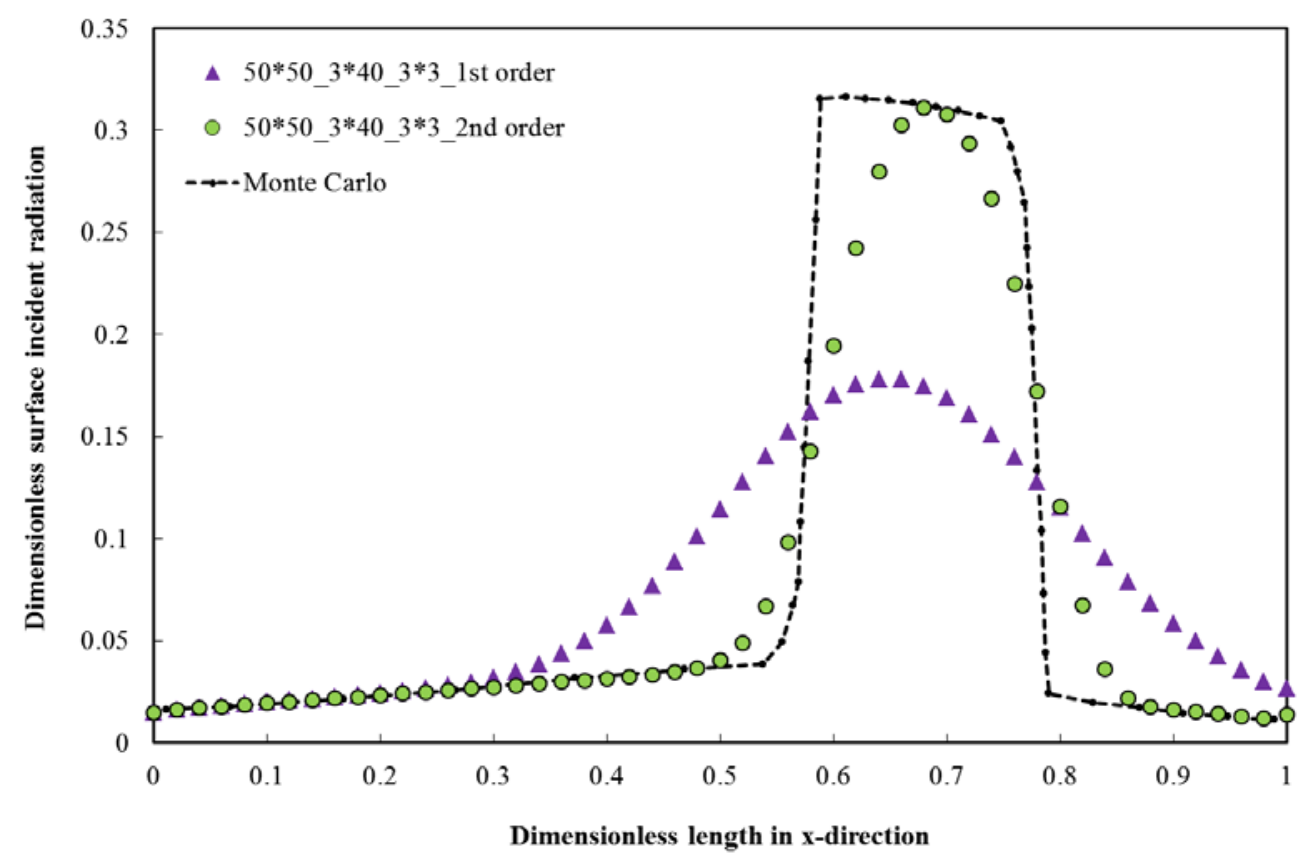

c)

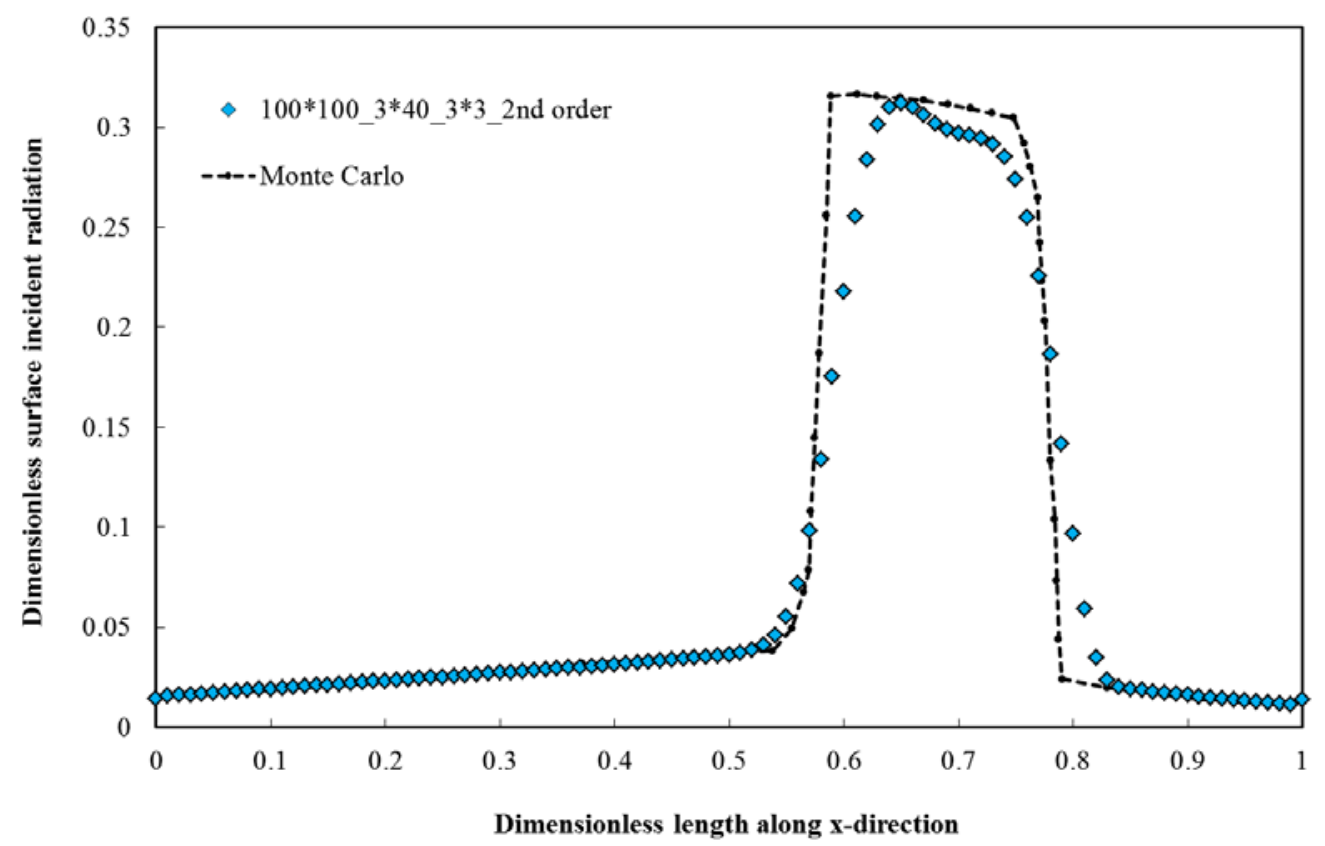

d)

Figure 2: Variation of a) angular discretisation, b) mesh density, c) discretisation order, d) optimal combination of settings; for oblique collimated radiation test case, as compared with Monte Carlo solution (Li, 2004) 
transparent section of the top wall $(0 \leq x \leq 0.2)$. The other walls of the enclosure are perfectly opaque and cold ( $0 \mathrm{~K}$ Temperature). The reason for choosing this case study was to see how well ANSYS Fluent deals with specular radiation with discontinuities (the expected step change in heat flux on the bottom wall).

A structured Cartesian mesh is used (as in Hachicha, 2013) in order to have an unaligned mesh with the incident radiation direction. This means that false scattering in the computational domain is expected.

The results are reported in Figure 2 and are compared with the Monte Carlo solution (Li, 2004). The following notation is used:

$N_{x} \times N_{y-} N_{\theta} \times N_{\phi-}$ Pixel $_{\theta} \times$ Pixel $_{\phi}$-Order of spatial discretisation on Discrete Ordinates

where the first two terms $\left(N_{x}, N_{y}\right)$ are the number of cells along $x$ - and $y$-directions, respectively, the next four specify the angular discretisation and pixellation in the two angular coordinates and the last term specifies either first, or second-order discretisation as available in ANSYS Fluent.

For this domain, the effect of varying the mesh density, then increasing the angular discretisation divisions, changing the discretisation order, and lastly, combining the optimal combination of these settings is illustrated in Figure 2 when using ANSYS Fluent. Note that the value of $N_{\theta}$ needs only to be set to 3 in the second dimension if the assumption of a 2-D planar coordinate system is valid. In Figure 2a, the ray effect due to an insufficient number of angular discretisations is obvious, as the focus of the incoming oblique ray misses the intended target as illustrated by the comparative accurate Monte Carlo ray-tracing solution. The ray effect error decreases with increasing $N_{\theta} \times N_{\phi}$ and the peak of each curve shifts towards the expected solution where due to heat flux step change (between $\mathrm{x}=0.577$ and $\mathrm{x}=0.777$ ), a peak in the curve is evident. Settings finer than $N_{\phi}=40$ do not result in a change in the peak location, implying that the ray effect error is minimised at this setting. However, it is clear that some false scattering remains.

In order to reduce the false scattering error, the effects of refining the spatial grid and using a more accurate spatial discretisation scheme for the sufficient ray effect reduction case $\left(N_{\phi}=40\right)$ are investigated separately in Figures $2 \mathrm{~b}$ and $2 \mathrm{c}$, respectively. The reduction in the smearing of the wave front is noted as the mesh is refined (Figure 2b), but the sharp discontinuity in absorbed radiation is not captured, even for the finest mesh (8-fold increase).

Second-order discretisation improves the smearing in a marked fashion. Figure 2c shows that switching to second-order spatial discretisation sharpens the peak even for the coarsest mesh $(50 * 50)$ for the case that reduced the ray effect error ( $3 * 40 \_3 * 3$ for angular discretisation), but it does not perfectly predict Monte Carlo solution, which exhibits a flat peak. Finally, by combining all the above methods, the false scattering and ray effect can be significantly reduced, with the discontinuity captured to some extent (Figure 2d).

In summary, ANSYS Fluent has the ability to lead to a reasonable solution of even a specular radiation case. Other FV implementations have attempted to reduce false scattering, e.g. Li et al. 
(2002) with their Double Ray Method (DRM), but implementation in three dimensions was problematic (Li, 2004).

Now the question remains whether previous researchers have implemented DO and FV in solar applications. If so, what are the main obstacles for using an FV DO solution of the RTE?

The obstacles are as follows: 1) ensuring the accuracy by using an appropriate FV mesh and angular discretisation, and 2) considering the associated computational cost.

Hachicha (2013) tried to solve the accuracy question by implementing an RTE solver that separates collimated and diffuse radiation for different spatial and angular discretisations. This method is similar to the Modified Discrete Ordinates Method (Ramankutty and Crosbie, 1998) where the intensity is split into a direct and diffuse component. Hachicha (2013) was able to significantly reduce false scattering and the ray effect for the test case displayed in Figure 1, even for a mesh of $25 \times 25$ and a $N_{\theta} \times N_{\phi}$ of 3x20 using this approach. Unfortunately, this split method is not currently available in ANSYS Fluent.

Being aware of the sufficient discretisation level for accuracy can result in large computational savings, e.g. Martinek and Weimer (2013) used DO and FV in a high-temperature solar thermal process application and compared the results with those obtained using Monte Carlo. The simulation of their model was done in ANSYS Fluent as in the current paper. Spatial and angular discretisations were chosen for the simulation of a 2-D closed cavity with a single-tube and a five-tube configuration as follows: four unstructured grids ranging from 2,364 to 132,453 elements and control angle increments $\left(N_{\theta} \times N_{\phi}\right)$ of $5 * 5,15 * 15$ and $25 * 25$ with $3 * 3$ pixellation in each case. According to Martinek and Weimer (2013), approximate solution times for the five-tube cavity increased from 11 to 1,000s and 270 to 20,000s, respectively, for the coarsest and finest mesh when changing from a $5 * 5$ to $25 * 25$ combination for $N_{\theta} \times N_{\phi}$. The corresponding Monte Carlo solution varied between 11,000 to 30,000s depending on the configuration and boundary conditions. As shown in Figure 2 above, Hachicha (2013) and later in Figure 11 for a much more complicated 2-D geometry, when a planar 2-D domain is considered, only three angular increments are required for the second ordinate direction. This means that the $25 * 25$ increments used by Martinek and Weimer (2013) were unnecessary and resulted in a computational cost of $4 * 25 * 25$ versus $4 * 3 * 25$, an increase by a factor of more than 8.

However, the studies of both Hachicha (2013) and Martinek and Weimer (2013) are good examples of the applicability of the DO solution using FV for solar applications. Both compared results with the Monte Carlo solution. The remaining question is whether a commercial CFD solver, e.g. ANSYS Fluent, is suitable for modelling solar applications, especially those of reflected solar irradiation in CSP line-focus systems. In the following section, this fact is surveyed to verify the applicability of ANSYS Fluent for the optical modelling of an LFC configuration. 


\subsection{LFC Layout and its ray-tracing modelling in SolTrace and ANSYS Fluent}

\subsubsection{LFC layout}

An LFC is a combination of an array of linear primary mirrors, which concentrates solar rays on a cavity receiver mounted at a specific height. Therefore, the optical efficiency of such plants is affected by different field factors such as primary mirror positions, width and space, while their thermal efficiency is affected by cavity factors such as the position of tube/tubes, insulation thickness and geometry of cavity. Therefore, in order to determine both the optical and thermal efficiency of such a plant, and to conduct optimisation studies, the cavity receiver and solar field must be defined completely.

The cavity receiver considered in this study is covered by a glass panel and is not evacuated. The glass window has interesting properties. Glass is opaque to high-wavelength radiation and semitransparent for the rest of the spectrum resulting in the so-called greenhouse effect. The solar irradiation reflected by the LFC mirror field passes through the glass with a small proportion being absorbed depending on the specified absorption coefficient. It then impacts the absorber pipes that are opaque to radiation and are coated with a specific solar-absorbing coating to absorb more solar energy (in the short-wavelength spectrum) but to re-radiate less energy to their surroundings as their temperature increases (in the high-wavelength spectrum). The portion of the energy not absorbed by the pipes is reflected towards the cavity side walls and back to the glass. The side walls are insulated to limit heat loss. These cavity side walls and pipe surfaces are opaque and both diffusely and specularly reflective, i.e. they absorb radiation and reflect it in a way that depends on the incident radiation wavelength, which interacts with the surface roughness height such that reflection is either specular of diffuse.

In this study, a solar mirror field (mirror width, mirror gap and number of mirrors) is considered based on what was defined in the FRESDEMO project (Mertins, 2009; Bernhard et al., 2008). The multi-tube trapezoidal cavity receiver considered here is close to initial case used by Moghimi et al. (2014, 2015) as displayed in Figure 3. A parallel four-tube bundle with pipes made of carbon steel (solid grey area in zoomed-in region of Figure 3) is located in a trapezoidal cavity that is filled with air. The cavity side and top walls are insulated insulation of different thickness (dotted area in zoomed-in region of Figure 3). The cavity aperture (lower wall) is covered by a $3.2 \mathrm{~mm}$-thick glass (not shown). The mirror field of width $W$ is located a distance $H$ below the pipe centre line with the individual mirror width indicated. The cavity geometry is parameterised with the values and definitions summarised in Table 2.

\subsubsection{LFC radiation modelling in SolTrace}

Because of the abovementioned shortcomings of the FV solution of the RTE and the uncertainty whether they can be resolved for a more complex solar geometry, an alternate analysis that uses Monte Carlo ray tracing is also required for the optical performance of the chosen LFC layout. Bode and Gauché (2012) considered SolTrace (a free ray-tracing software tool developed by the National Renewable Energy Laboratory (NREL, 2014)), suitable for complex optical modelling 


\begin{tabular}{|l|l|l|l|l|l|}
\hline \multicolumn{5}{|c|}{ Table 2: Geometrical parameters of LFC with parameter values for parameters indicated in } \\
Figure 3 & 55 \\
\hline $\begin{array}{l}\text { Number of primary } \\
\text { mirrors }\end{array}$ & 25 & Pipe thickness $(t[\mathrm{~mm}])$ & 5 & $\begin{array}{l}\text { Pipe offset from top } \\
\text { wall }(d[\mathrm{~mm}])\end{array}$ & 75 \\
\hline $\begin{array}{l}\text { Solar field width } \\
(W[\mathrm{~m}])\end{array}$ & 21 & Pipe ID $(\mathrm{ID}[\mathrm{mm}])$ & 40 & $\begin{array}{l}\text { Pipe offset from each } \\
\text { pipe }(m[\mathrm{~mm}])\end{array}$ & 75.5 \\
\hline $\begin{array}{l}\text { Primary mirror width } \\
(w[\mathrm{~m}])\end{array}$ & 0.6 & $\begin{array}{l}\text { Cavity top side width } \\
(c[\mathrm{~mm}])\end{array}$ & 400 & $\begin{array}{l}\text { Biggest distance of pipe } \\
\text { centre from cavity } \\
\text { centre }(p[\mathrm{~mm}])\end{array}$ & 112.5 \\
\hline $\begin{array}{l}\text { Receiver height }(H[\mathrm{~m}]) \\
\text { Side insulation }\end{array}$ & 40 & $\theta_{1}\left[^{\circ}\right]$ & 240 & $\begin{array}{l}\text { Top insulation thickness } \\
(f[\mathrm{~mm}])\end{array}$ & 85 \\
\hline thickness $(a[\mathrm{~mm}])$ & 30 & $\theta_{2}\left[^{\circ}\right]$ & 60 \\
\hline
\end{tabular}




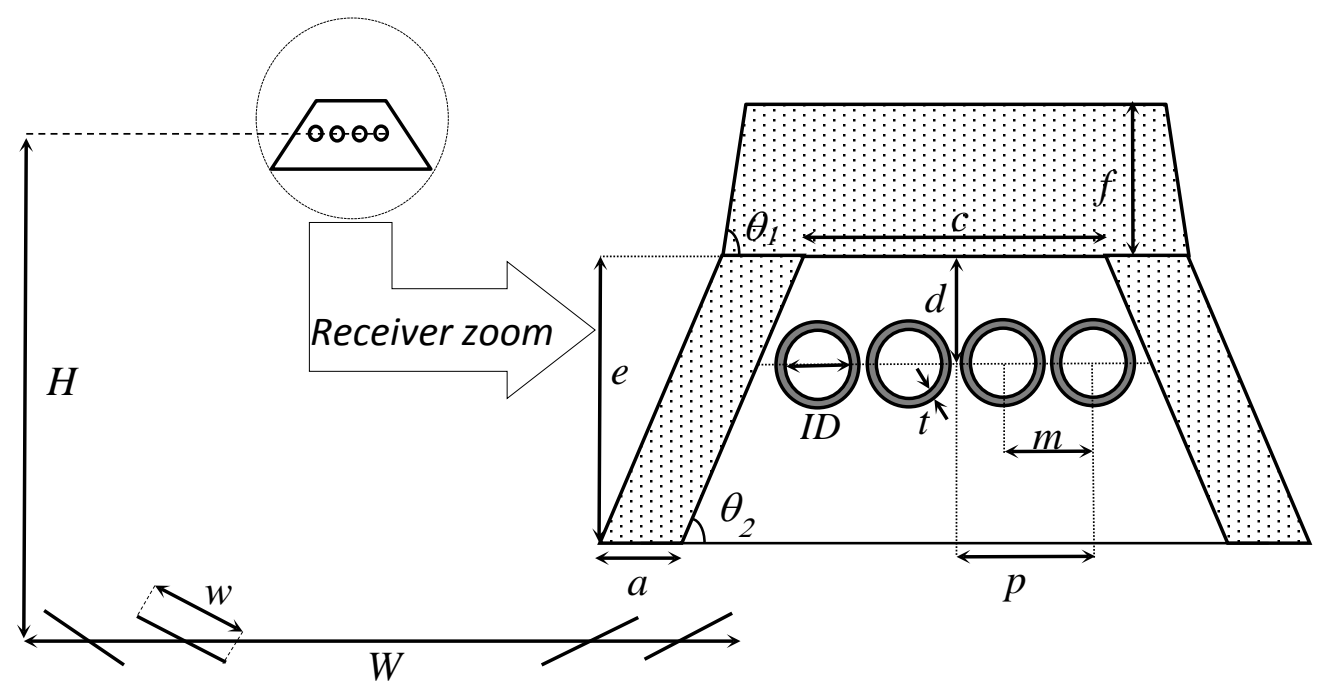

Figure 3: Schematic layout of the LFC mirror field and cavity receiver 

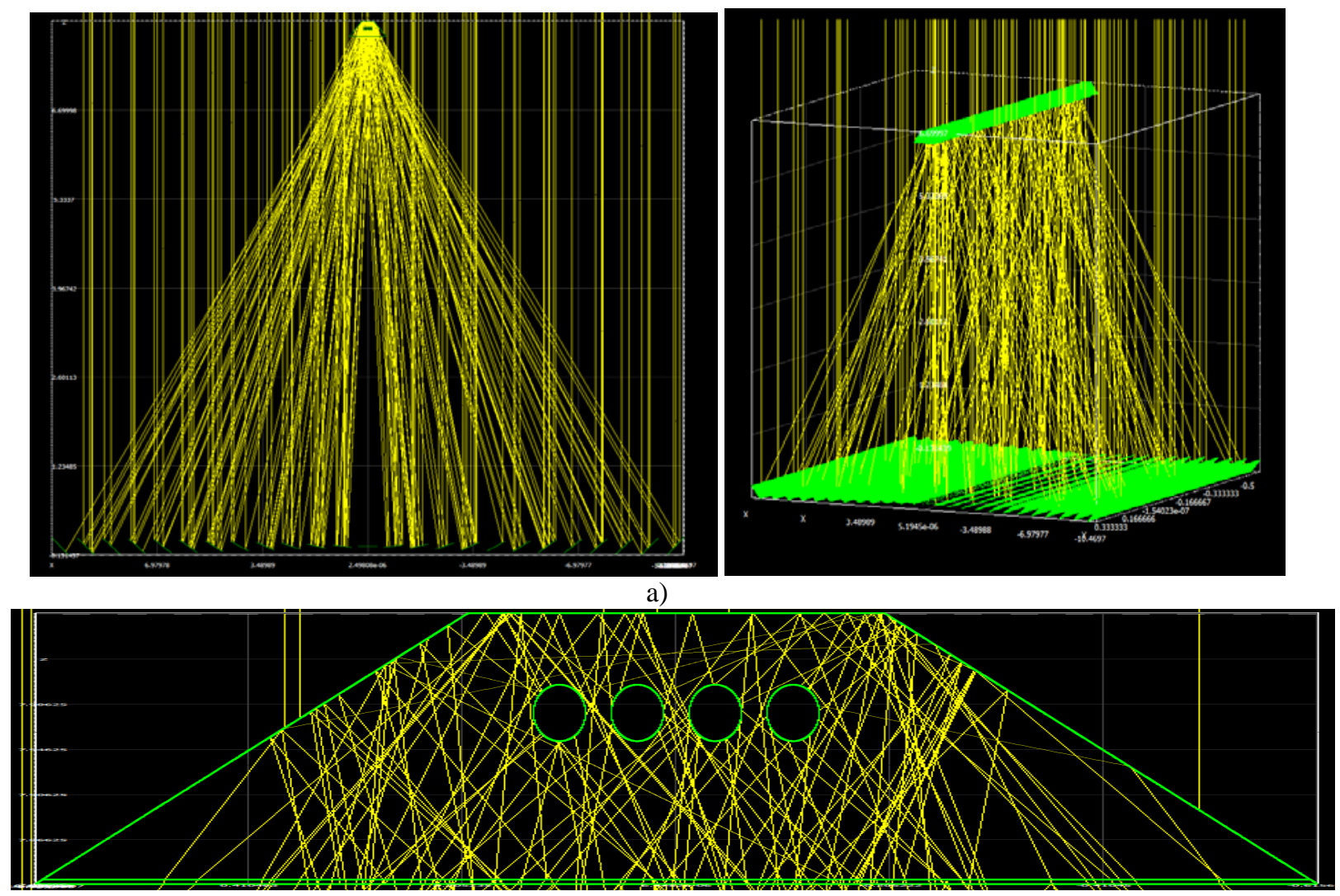

b)

Figure 4: Ray tracing for the LFC layout in SolTrace a) Entire optical domain (front and isometric view), b) Zoomed-in view of cavity receiver with four pipes 


\begin{tabular}{|l|l|l|l|}
\hline \multicolumn{4}{|c|}{ Table 3: SolTrace parameters for LFC optical modelling } \\
\hline Sun shape & Gaussian & 2.63 mrad & z-direction (noon) \\
\hline Primary mirrors & Reflectivity $=1$ & Slope error $=0.0001$ & $\begin{array}{l}\text { Specularity error }= \\
0.0001\end{array}$ \\
\hline Tubes & Reflectivity $=0.05$ & & \\
\hline Glass & Transmissivity $=1$ & Refraction ratio $=1.5$ & \\
\hline Cavity side walls & Reflectivity $=0.95$ & & \\
\hline $\begin{array}{l}\text { Direct normal } \\
\text { irradiation (DNI) }\end{array}$ & $1,000 \mathrm{~W} / \mathrm{m}^{2}$ & & \\
\hline
\end{tabular}


and evaluating CSP plant performance. The main drawback of this software is the manual definition of surfaces based on sun position, which is not user-friendly.

A SolTrace model was constructed of the proposed LFC layout, with the optical parameters summarised in Table 3. For more information on how to simulate an LFR setup in Soltrace refer to section 2 of the supplementary material.

Based on the geometrical definition of solar field and the SolTrace settings, a sample solution of ray trace is shown in Figure 4. Individual rays (vertical yellow lines) trace downwards from the noon position of the sun and reflect off the linear mirror segments (green segments at the bottom Figure 4a) and concentrating upwards onto the tubes enclosed with a trapezoidal cavity wall and glass cover (Figure 4b).

For assurance of SolTrace solution convergence, the "Desired number of ray intersections" parameter in SolTrace was increased until the average heat flux value on each individual pipe stabilised and its symmetrical counterpart converged to the same value. The average heat flux absorbed by all four pipes was monitored as well. The convergence results are summarised in Table 4 and Figure 5.

Due to the symmetry of the geometry, the average value of the absorbed heat flux for the symmetrical pipes ( $2 \& 3$ and $1 \& 4$ ) has to be the same. Table 4 shows that by increasing the "Desired number of ray intersections", the results of symmetrical pipes converge to numbers that are similar but not exact because of the Monte Carlo process. Even for the minimum "Desired number of ray intersections" value, the average value of the heat flux is well predicted, but not necessarily symmetrically distributed. Based on Table 3 and Figure 5, apparently a ray count of $1,000,000$ can be considered as providing a converged solution for the average value.

However, the circumferential distribution of the ray hits is another parameter that must be considered for cavity performance evaluation. SolTrace outputs ray data that can be further postprocessed. These data are a set of intersection points and direction cosines. Using a VBA (Visual Basic for Application) code written in Microsoft Excel and Microsoft Access, the number of ray hits on a certain circumferential increment of each pipe was calculated and converted using the power per ray value to an equivalent heat flux. The resulting circumferential distribution of the heat flux for the 3rd and 4th pipe obtained using SolTrace is depicted in Figure 6 for different desired ray intersections ranging from 5,000 to $1,000,000$. The origin of the circumferential coordinate is indicated in the insert.

It can be seen that by increasing the desired number of rays, the fluctuations in the distribution decrease as the stochastic nature of the Monte Carlo process provides a more distributed profile with an increasing ray count. The presence of the oblique corner of the cavity close to the 4th pipe leads to an interesting phenomenon in the range 0 to $100^{\circ}$ (Figure 6b). The heat flux trend was underestimated until the ray count reached 500,000. For ray counts more than 1,000,000 (not shown), the distribution remained unchanged. For both distributions, the heat flux was a maximum at $180^{\circ}$ (the bottom of the pipes) as expected, but the mostly reflecting side and top walls resulted in significant heat absorption on the upper parts of the pipes as well. 


\begin{tabular}{|c|c|c|c|c|c|c|c|}
\hline \multicolumn{8}{|c|}{ Table 4:Convergence study of SolTrace } \\
\hline $\begin{array}{l}\text { Desired number of } \\
\text { ray intersections }\end{array}$ & Ray count & $\begin{array}{l}\text { Power per } \\
\text { ray }\end{array}$ & $\begin{array}{c}\text { Ave. heat } \\
\text { flux on the } \\
1^{\text {st }} \text { pipe } \\
\text { from left to } \\
\text { right }\end{array}$ & $\begin{array}{l}\text { Ave. heat } \\
\text { flux on the } \\
2^{\text {nd }} \text { pipe } \\
\text { from left to } \\
\text { right }\end{array}$ & $\begin{array}{c}\text { Ave. heat } \\
\text { flux on the } \\
3^{\text {rd }} \text { pipe } \\
\text { from left to } \\
\text { right }\end{array}$ & $\begin{array}{c}\text { Ave. heat } \\
\text { flux on the } \\
4^{\text {th }} \text { pipe } \\
\text { from left to } \\
\text { right }\end{array}$ & $\begin{array}{c}\text { Average of } \\
\text { all heat } \\
\text { fluxes on } \\
\text { pipes }\end{array}$ \\
\hline 5,000 & 11,393 & 3.00273 & 11,8167 & 11,159 & 10,829 & 11,670 & 11,369 \\
\hline 10,000 & 23,022 & 1.48597 & 11344 & 11,185 & 10,609 & 11,434 & 11,143 \\
\hline 50,000 & 116,066 & 0.294747 & 11,829 & 10,741 & 10,944 & 11,425 & 11,235 \\
\hline 100,000 & 231,347 & 0.147874 & 11,660 & 10,995 & 10,815 & 11,644 & 11,279 \\
\hline 500,000 & $1,152,422$ & 0.0296854 & 11,850 & 10,893 & 10,946 & 11,865 & 11,388 \\
\hline $1,000,000$ & $2,307,140$ & 0.0148279 & 11,773 & 10,957 & 10,941 & 11,814 & 11,371 \\
\hline $2,000,000$ & $4,615,871$ & 0.00741141 & 11,751 & 10,972 & 10,985 & 11,788 & 11,374 \\
\hline
\end{tabular}




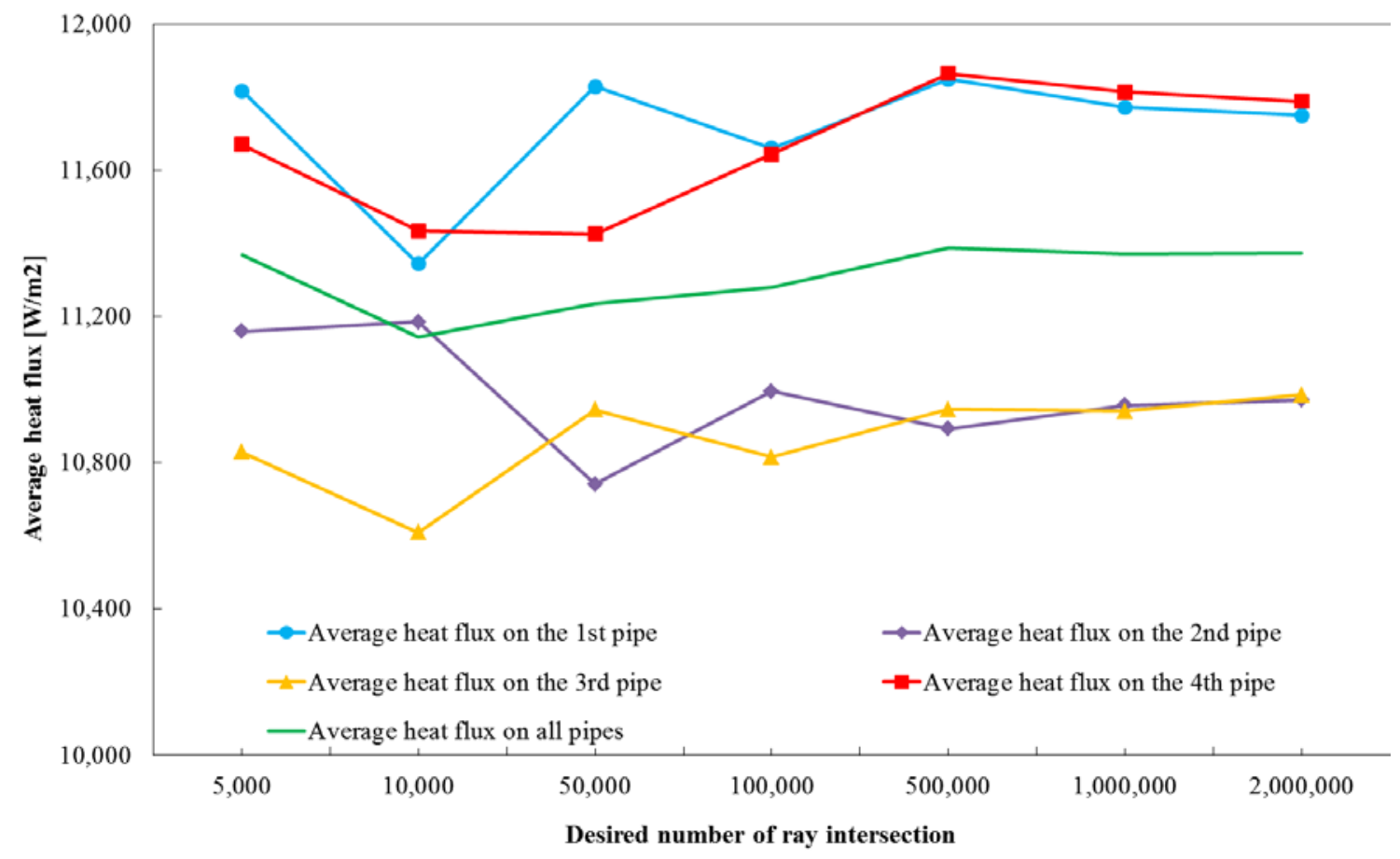

Figure 5: Convergence study of average heat flux on absorber pipes in SolTrace 


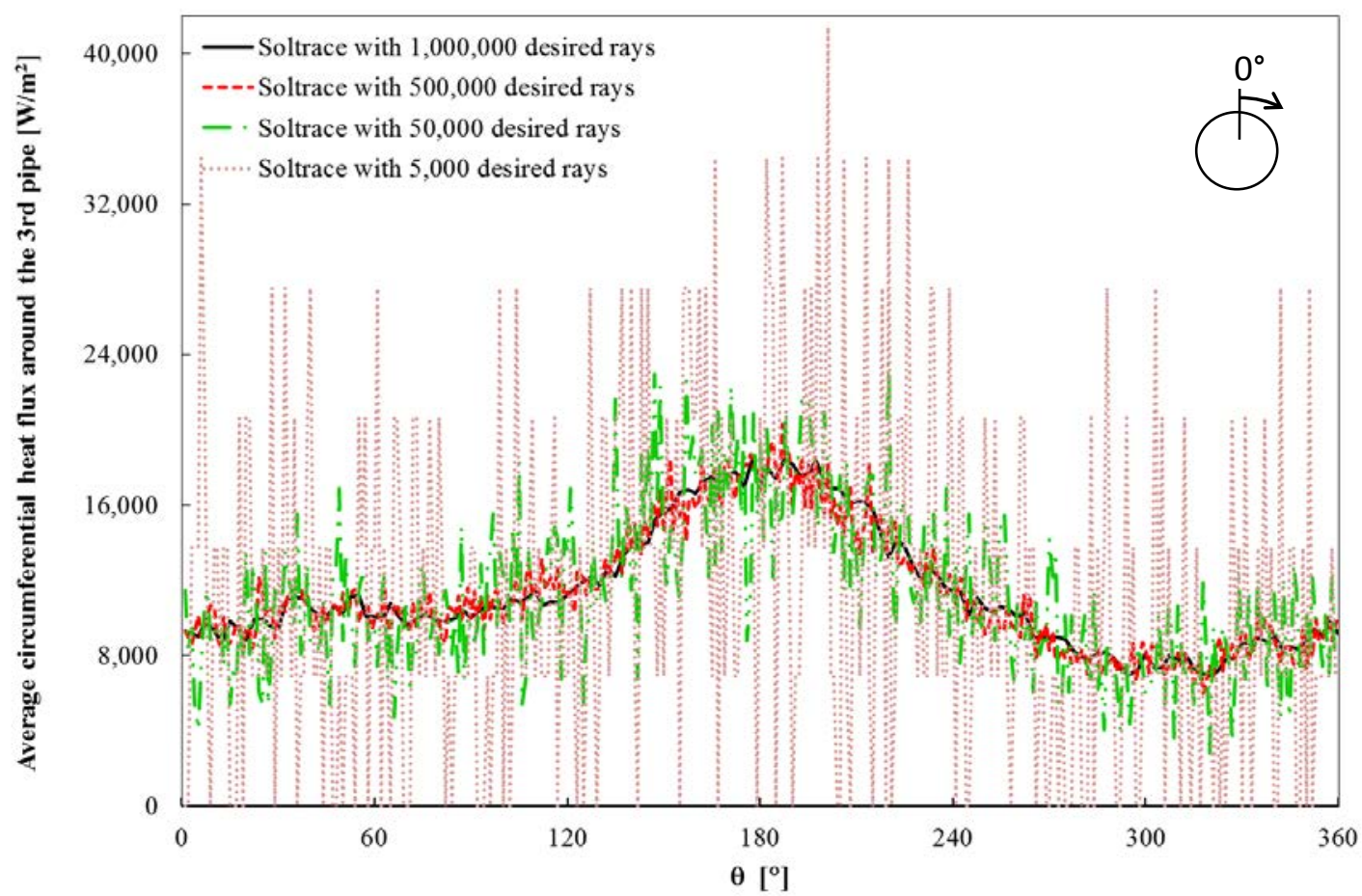

a) Average circumferential heat flux $\left[\mathrm{W} / \mathrm{m}^{2}\right]$ around the 3rd pipe

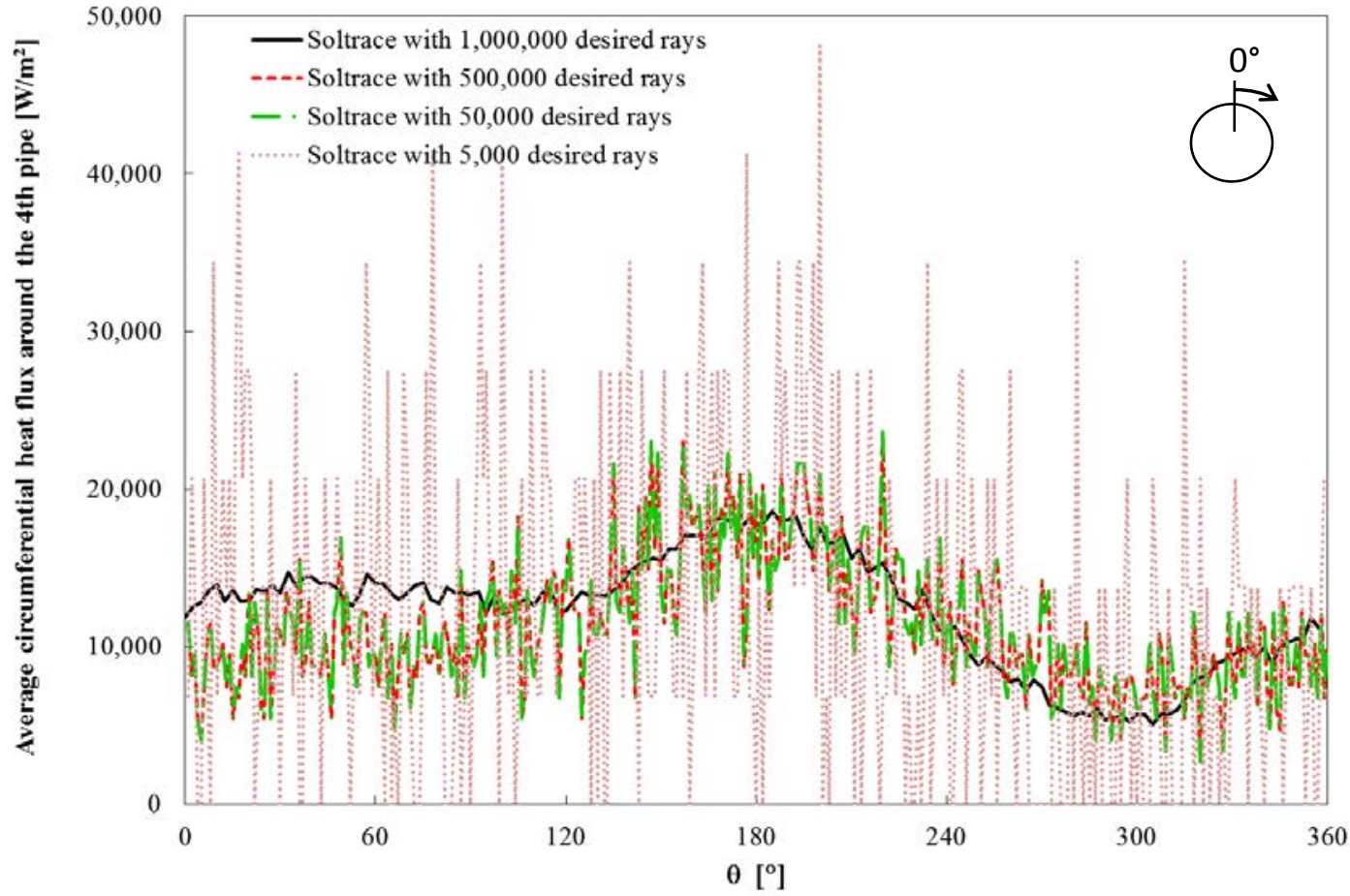

b) Absorbed circumferential heat flux $\left[\mathrm{W} / \mathrm{m}^{2}\right]$ around the 4 th pipe Figure 6: Fluctuation of SolTrace results for different desired rays 


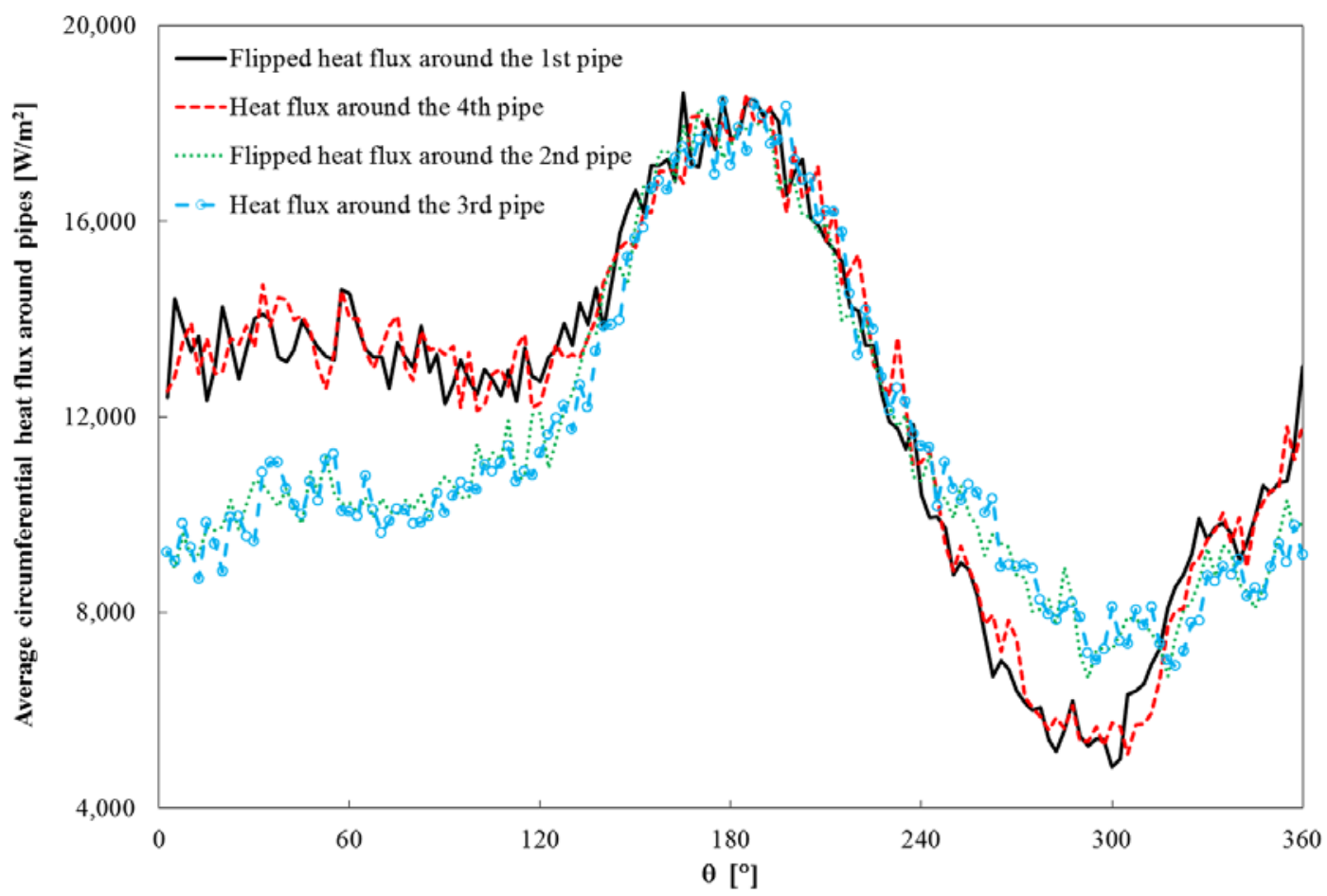

Figure 7: Checking the symmetrical nature of the circumferential pipe heat flux distributions 
By increasing the number of desired ray intersections, the symmetrical property of the absorbed heat flux is also ensured. Figure 7 illustrates the symmetrical result by flipping the results of the 1st and 2nd pipe and superimposing them on the 4th and 3rd pipe, respectively. This comparison is made for 1 million desired ray intersections.

\subsubsection{LFC radiation modelling in ANSYS Fluent}

Given the converged SolTrace solutions of the previous section, the question now remains how accurately ANSYS Fluent (by using the DO FV method of solving the RTE) can predict these distributions. In other words, is an FV solver able of accurately predicting a RTE solution?

Apart from Martinek and Weimer (2013), who also used ANSYS Fluent to determine the heat flux distribution, other solar cavity researchers mostly used a Monte Carlo ray tracer to capture the non-uniform heat flux of more complex geometries (e.g. Wirz et al., 2014; Ghadirijafarbeigloo et al., 2014; Cheng et al., 2012 and He et al., 2011). These researchers used SolTrace or another Monte Carlo code to capture the non-uniform solar heat flux on the absorber pipe of a parabolic trough collector and then with additional software map their results into the fluid flow domain for a computational thermal simulation. The following section describes the use of ANSYS Fluent as an accurate FV solver to calculate the non-uniform heat flux distribution of the LFC cavity receiver and mirror field, an application which was not considered by previous researchers .

\subsubsection{Optical geometry and meshing}

To perform the optical modelling of the LFC layout based on the specifications listed in Table 2, a symmetrical 2-D model of the entire optical domain was created in ANSYS Workbench (ANSYS, 2013c) and meshed in the ANSYS Meshing tool (ANSYS 2013c). The geometry and meshes are displayed in Figure 8. The top boundary is a semi-transparent wall where the solar irradiation enters the domain. The mirrors form the lower boundary together with the gaps between them. The latter as well as the right edge of the domain are modelled as black bodies that capture all the radiative energy reaching them. The left edge of the domain is a symmetry edge, providing pure reflection. The cavity was modelled with glass covering its aperture and surrounded by insulation (required for the thermal modelling to follow). The pipes are modelled with only their outer surface to provide a boundary condition where the resulting fluxes can be obtained. Figure $8 \mathrm{~b}$ shows the 86,725 cell mesh (refer to Table 7).

\subsubsection{Boundary conditions and material properties of optical modelling}

The assumption can be made that air is transparent to radiation and that the effect of convective heat transfer on solar irradiation has only to be incorporated when considering conjugate heat transfer (section 3). As such, the air between the mirror field and cavity and inside the cavity is modelled as a solid with the thermal properties of air and being transparent to radiation (absorption coefficient of 0 ). This means that only the RTE and energy equations need to be solved in the computational domain, which reduces the computational overhead significantly. In 

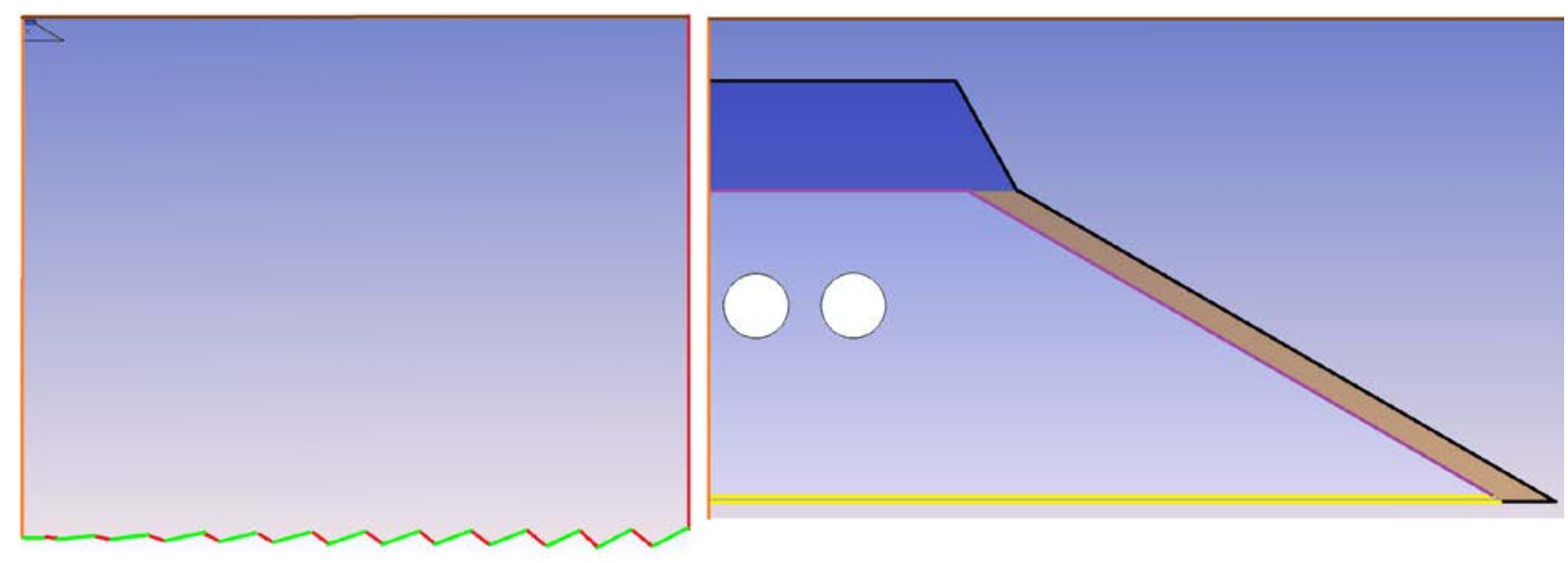

(a)
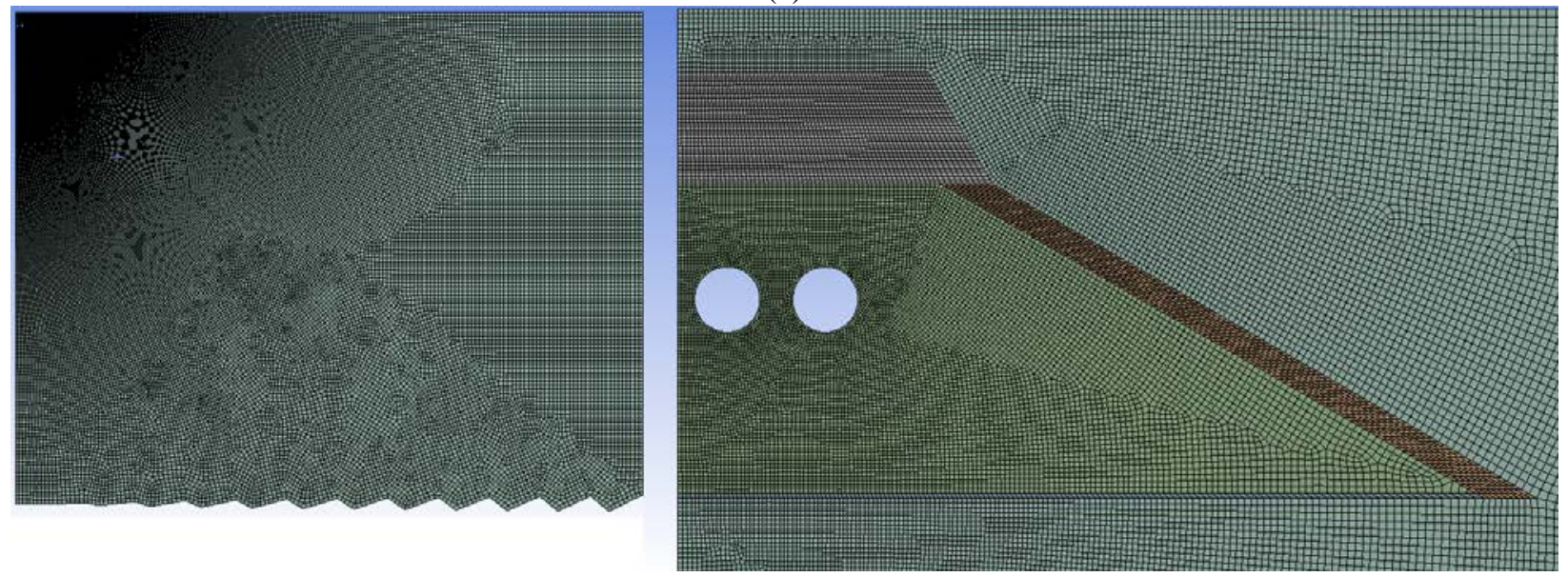

(b)

Figure 8: a) CFD model of optical geometry of LFC (whole symmetrical domain - left, zoomedin view of cavity receiver - right), b) Mesh of optical geometry of LFC (whole symmetrical domain - left, zoomed-in view of cavity receiver - right) 


\begin{tabular}{|c|c|c|c|c|}
\hline \multicolumn{5}{|c|}{ Table 5: Material properties } \\
\hline Material & $\begin{array}{l}\text { Participating } \\
\text { in radiation }\end{array}$ & $\begin{array}{c}\text { Absorption } \\
\text { coefficient } \\
{\left[\mathrm{m}^{-1}\right]}\end{array}$ & $\begin{array}{l}\text { Refractive } \\
\text { index }\end{array}$ & Other \\
\hline $\begin{array}{l}\text { Solid air } \\
\text { in and around cavity }\end{array}$ & Yes & 0 & 1 & $\begin{array}{c}\text { Thermal conductivity }=0.0242 \\
{[\mathrm{~W} / \mathrm{m}-\mathrm{K}],} \\
\text { Specific heat }=1006.43[\mathrm{~J} / \mathrm{kg}-\mathrm{K}] \\
\text { Density }=1.225\left[\mathrm{~kg} / \mathrm{m}^{3}\right]\end{array}$ \\
\hline Semi-transparent glass & Yes & 106 & 1.5 & $\begin{array}{l}\text { Thermal conductivity }=1.5[\mathrm{~W} / \mathrm{m}- \\
\text { K], } \\
\text { Specific heat }=786[\mathrm{~J} / \mathrm{kg}-\mathrm{K}] \\
\text { Density }=2650\left[\mathrm{~kg} / \mathrm{m}^{3}\right]\end{array}$ \\
\hline $\begin{array}{l}\text { Insulation-glass wool } \\
\text { (TIASA, 2001) }\end{array}$ & No & 0 & 1 & $\begin{array}{c}\text { Thermal conductivity = } \\
\text { piecewise-linear }[\mathrm{W} / \mathrm{m}-\mathrm{K}] \text {, } \\
\text { Specific heat }=446[\mathrm{~J} / \mathrm{kg}-\mathrm{K}] \text {, } \\
\text { Density }=48\left[\mathrm{~kg} / \mathrm{m}^{3}\right]\end{array}$ \\
\hline
\end{tabular}




\begin{tabular}{|c|c|c|c|c|c|}
\hline \multicolumn{6}{|c|}{ Table 6: Boundary conditions for optical domain } \\
\hline Surface & BC type & $\begin{array}{l}\text { Thermal } \\
\text { condition }\end{array}$ & $\begin{array}{c}\text { Temperature } \\
{[\mathrm{K}]}\end{array}$ & Emissivity & Others \\
\hline $\begin{array}{l}\text { Solar field top } \\
\text { side }\end{array}$ & $\begin{array}{c}\text { Semi- } \\
\text { transparent }\end{array}$ & $\begin{array}{c}\text { Constant } \\
\text { temperature }\end{array}$ & 1 & 1 & $\begin{array}{c}\text { Beam width } \\
\theta=0.53^{\circ} \& \phi=0.53^{\circ}, \\
\text { Direct Irradiation }=1,000\left[\mathrm{~W} / \mathrm{m}^{2}\right] \\
\text { downwards }\end{array}$ \\
\hline $\begin{array}{l}\text { Solar field right } \\
\text { side and gaps } \\
\text { between } \\
\text { mirrors }\end{array}$ & $\begin{array}{l}\text { Opaque and } \\
\text { black body }\end{array}$ & $\begin{array}{c}\text { Constant } \\
\text { temperature }\end{array}$ & 1 & 1 & - \\
\hline Mirrors & $\begin{array}{c}\text { Opaque and } \\
\text { pure reflective }\end{array}$ & $\begin{array}{c}\text { Constant } \\
\text { temperature }\end{array}$ & 1 & 0 & - \\
\hline $\begin{array}{l}\text { Solar field left } \\
\text { side }\end{array}$ & Symmetry & - & - & - & - \\
\hline $\begin{array}{c}\text { External } \\
\text { surfaces of } \\
\text { insulation }\end{array}$ & Opaque & $\begin{array}{c}\text { Constant } \\
\text { temperature }\end{array}$ & 1 & 1 & - \\
\hline Cavity walls & $\begin{array}{l}\text { Opaque and } \\
\text { reflective }\end{array}$ & $\begin{array}{c}\text { Constant } \\
\text { temperature }\end{array}$ & 1 & .05 & - \\
\hline Glass sides & $\begin{array}{c}\text { Semi- } \\
\text { transparent }\end{array}$ & Coupled & - & 0 & - \\
\hline $\begin{array}{c}\text { Outer surface } \\
\text { of pipes }\end{array}$ & $\begin{array}{l}\text { Opaque with } \\
\text { selective } \\
\text { coating }\end{array}$ & $\begin{array}{c}\text { Constant } \\
\text { temperature }\end{array}$ & 1 & 0.95 & - \\
\hline
\end{tabular}


addition, to isolate the solar load, all opaque walls in the domain are modelled as cold, having a specified temperature of $1 \mathrm{~K}$. This eliminates any thermal re-radiation.

For this optical modelling, the glass cover needs special treatment. The glass zone is modelled as two semi-transparent walls containing a solid medium which participates in radiation. Firstly, glass provides refraction of which the effect would be dependent on its thickness. Secondly, this medium is almost opaque to the higher wavelength band of radiation $(>\sim 4 \mu \mathrm{m})$ while it is almost semi-transparent to lower wavelengths, which leads to the greenhouse effect. This phenomenon can be modelled accurately based on the definition of dual-band absorption coefficient (Moghimi et al., 2014, 2015) in ANSYS Fluent DO implementation. However, because the current optical model does not consider re-radiation (to be included in the conjugate heat transfer model in section 3), a single band can be used for this evaluation. The material properties used are summarised in Table 5. The insulation properties are given here for completeness and will be used in the thermal evaluation to follow. The boundary conditions for the optical domain are summarised in Table 6.

\subsubsection{Mesh and angular independence}

Based on what was discussed in Section 2.2, a mesh and angular discretisation independence study is required to determine the correct settings for an accurate ANSYS Fluent simulation. For this study, a second-order upwind discretisation was used for the DO calculations. All simulations were run for 2,000 iterations to ensure that the normalised residual for DO was less than 1e-6 and stable monitors on the area-weighted average absorbed the heat flux on each pipe. The results are reported in Tables 7 and 8 for both mesh independence and angular independence, respectively. Figure 9 provides a graphic form of the tabular data with Figure 9a concentrating on the heat flux and Figure 9b on the computational cost. The wall clock time values are reported when running on 5 cores of an Intel core ${ }^{\mathrm{TM}}$ i7-3970X CPU with 32 GB RAM.

The 2nd to 4th columns of Table 7 provide proof that the mesh quality is consistent during the mesh refinement process. For the mesh refinement, the angular discretisation setting was kept constant at $3 * 30$ for $N_{\theta} \times N_{\phi}$ and $3 * 3$ pixels. An accurate ( $0 \%$ deviation) result was based on a $1,040,700$ cell case and the relative cost measure deemed this case $100 \%$ expensive.

The effect of varying the angular discretisation settings was investigated for a constant mesh count of 86,725 cells with a constant pixellation of the discrete ordinates of $3 * 3$ (Table 8). An $N_{\theta} \times N_{\phi}$ of $3 \times 400$ was considered to be the most accurate case ( $0 \%$ deviation) and the most expensive (100\%).

If a $1 \%$ accuracy level is deemed accurate enough, then a $3 * 200$ angular discretisation setting for a mesh count of 346,900 or more can be considered to be in the region of convergence. The graphic portrayal of the tabular data in Figure 9 confirms this conclusion and allows for the following observations to be made:

1. In Figure 9a, the variation in results when refining the control angle extension for a specific mesh count is much wider (almost three times) than the variation in results 


\begin{tabular}{|c|c|c|c|c|c|c|c|c|c|}
\hline \multicolumn{10}{|c|}{ Table 7: Mesh study } \\
\hline $\begin{array}{l}\text { Number of } \\
\text { cells }\end{array}$ & $\begin{array}{c}\text { Aspect } \\
\text { ratio }\end{array}$ & $\begin{array}{c}\text { Jacobian } \\
\text { ratio }\end{array}$ & $\begin{array}{c}\text { Mesh } \\
\text { quality }\end{array}$ & $\begin{array}{c}\text { Clock time } \\
{[\mathrm{s}]}\end{array}$ & $\begin{array}{c}\text { Area- } \\
\text { weighted } \\
\text { average of } \\
\text { absorbed } \\
\text { heat flux on } \\
\text { 3rd pipe } \\
\text { [W/m²] }\end{array}$ & $\begin{array}{c}\text { Area- } \\
\text { weighted } \\
\text { average of } \\
\text { absorbed } \\
\text { heat flux on } \\
\text { 4th pipe } \\
{\left[\mathrm{W} / \mathrm{m}^{2}\right]}\end{array}$ & $\begin{array}{c}\text { Average of } \\
\text { both pipes } \\
{\left[\mathrm{W} / \mathrm{m}^{2}\right]}\end{array}$ & \begin{tabular}{|c|} 
Deviation \\
percentage of \\
result accuracy \\
from levelling- \\
off case $\%$ \\
(based on \\
average of both \\
pipes)
\end{tabular} & $\begin{array}{l}\text { Computational } \\
\text { cost ratio } \\
\text { percentage in } \\
\text { comparison with } \\
\text { levelling-off cost } \\
\text { (based on CPU } \\
\text { time) }\end{array}$ \\
\hline 459 & 1.71 & 1.72 & 0.71 & 32.7 & 2,994 & 2,511 & 2,753 & -52.9 & 0.0 \\
\hline 1101 & 1.44 & 1.41 & 0.79 & 40.2 & 3,079 & 3,671 & 3,375 & -42.3 & 0.1 \\
\hline 2927 & 1.21 & 1.23 & 0.87 & 61.7 & 4,029 & 4,722 & 4,375 & -25.2 & 0.2 \\
\hline 7896 & 1.16 & 1.18 & 0.90 & 135.6 & 4,743 & 5,501 & 5,122 & -12.4 & 0.4 \\
\hline 86,725 & 1.08 & 1.05 & 0.96 & 1,286 & 5,384 & 6,062 & 5,723 & -2.1 & 3.5 \\
\hline 346,900 & \multicolumn{3}{|c|}{$\begin{array}{l}\text { By using Fluent mesh } \\
\text { adaptation }\end{array}$} & 5,188 & 5,506 & 6,108 & 5,807 & -0.7 & 14.0 \\
\hline $1,040,700$ & \multicolumn{3}{|c|}{$\begin{array}{l}\text { By using Fluent mesh } \\
\text { adaptation }\end{array}$} & 36,993 & 5,548 & 6,145 & 5,846 & 0 & 100 \\
\hline
\end{tabular}




\begin{tabular}{|c|c|c|c|c|c|c|}
\hline \multicolumn{7}{|c|}{ Table 8: Angular discretisation study } \\
\hline $\begin{array}{c}\text { DO } \\
\text { Discretisati } \\
\text { on setting } \\
N_{\theta} \times N_{\phi}\end{array}$ & Clock time [S] & 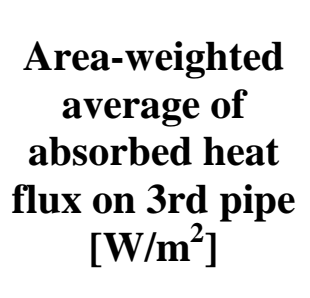 & $\begin{array}{c}\text { Area-weighted } \\
\text { average of } \\
\text { absorbed heat } \\
\text { flux on 4th pipe } \\
{\left[\mathrm{W} / \mathrm{m}^{2}\right]}\end{array}$ & $\begin{array}{c}\text { Average of both } \\
\text { pipes }\left[\mathrm{W} / \mathrm{m}^{2}\right]\end{array}$ & $\begin{array}{c}\text { Deviation } \\
\text { percentage from } \\
\text { levelling off \% } \\
\text { (based on average } \\
\text { of both pipes) }\end{array}$ & $\begin{array}{l}\text { Computational cost } \\
\text { ratio percentage in } \\
\text { comparison with } \\
\text { levelling-off cost } \\
\text { based on CPU } \\
\text { TIME }\end{array}$ \\
\hline $3 * 5$ & 234.4 & 859 & 1,144 & 1,001 & -88.9 & 1.5 \\
\hline $3 * 10$ & 436.9 & 2,039 & 2,357 & 2,198 & -75.7 & 2.7 \\
\hline $3 * 30$ & 1,286 & 5,384 & 6,062 & 5,723 & -36.7 & 8.0 \\
\hline $3 * 50$ & 2108 & 6,937 & 7,702 & 7,320 & -19.1 & 13.2 \\
\hline $3 * 100$ & 3,958 & 8,263 & 8,918 & 8,591 & -5.0 & 24.9 \\
\hline $3 * 200$ & 7,711 & 8,621 & 9,294 & 8,958 & -0.95 & 48.5 \\
\hline $3 * 400$ & 15,915 & 8,711 & 9,377 & 9,044 & 0.00 & 100.0 \\
\hline
\end{tabular}




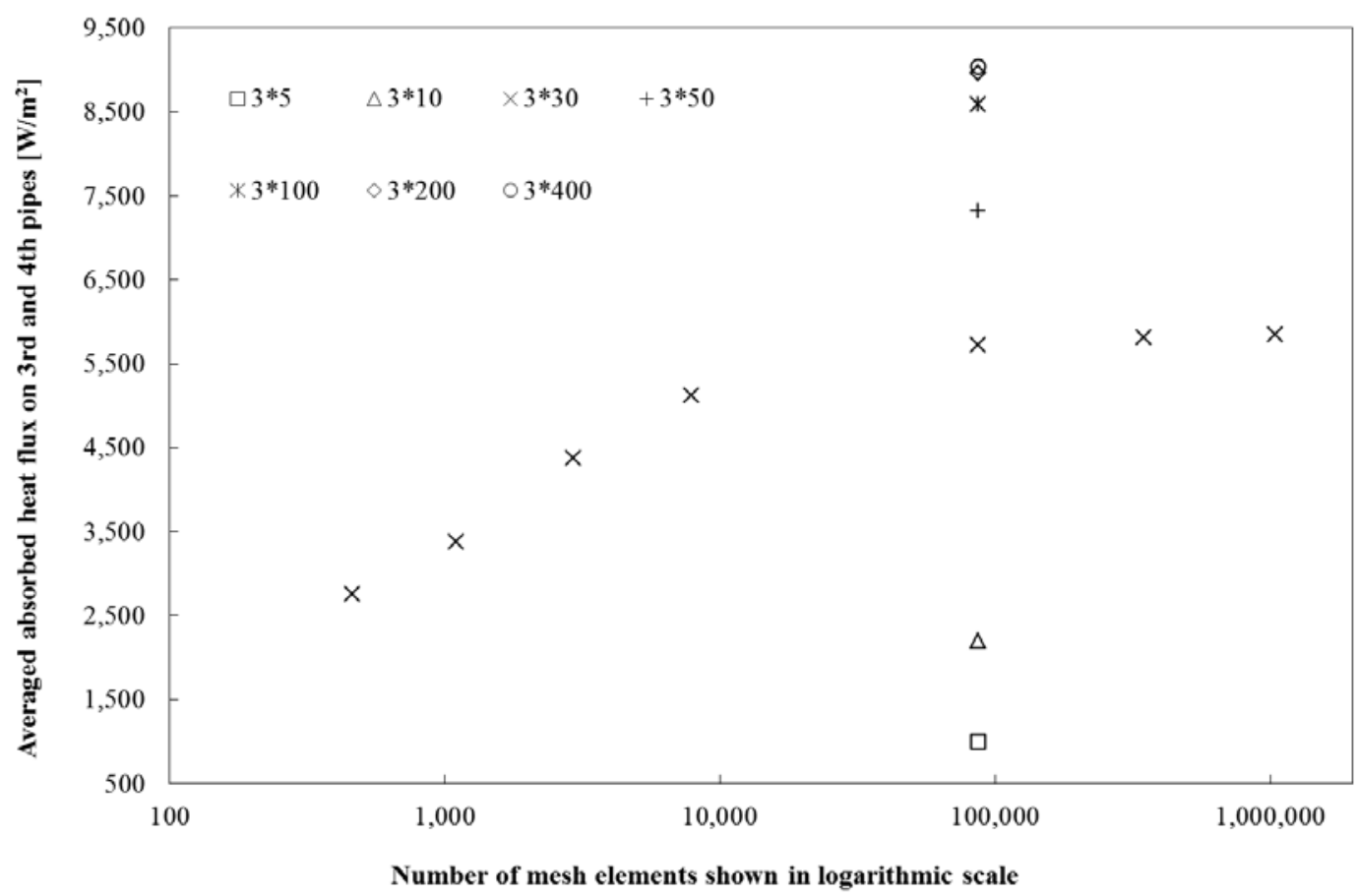

a)

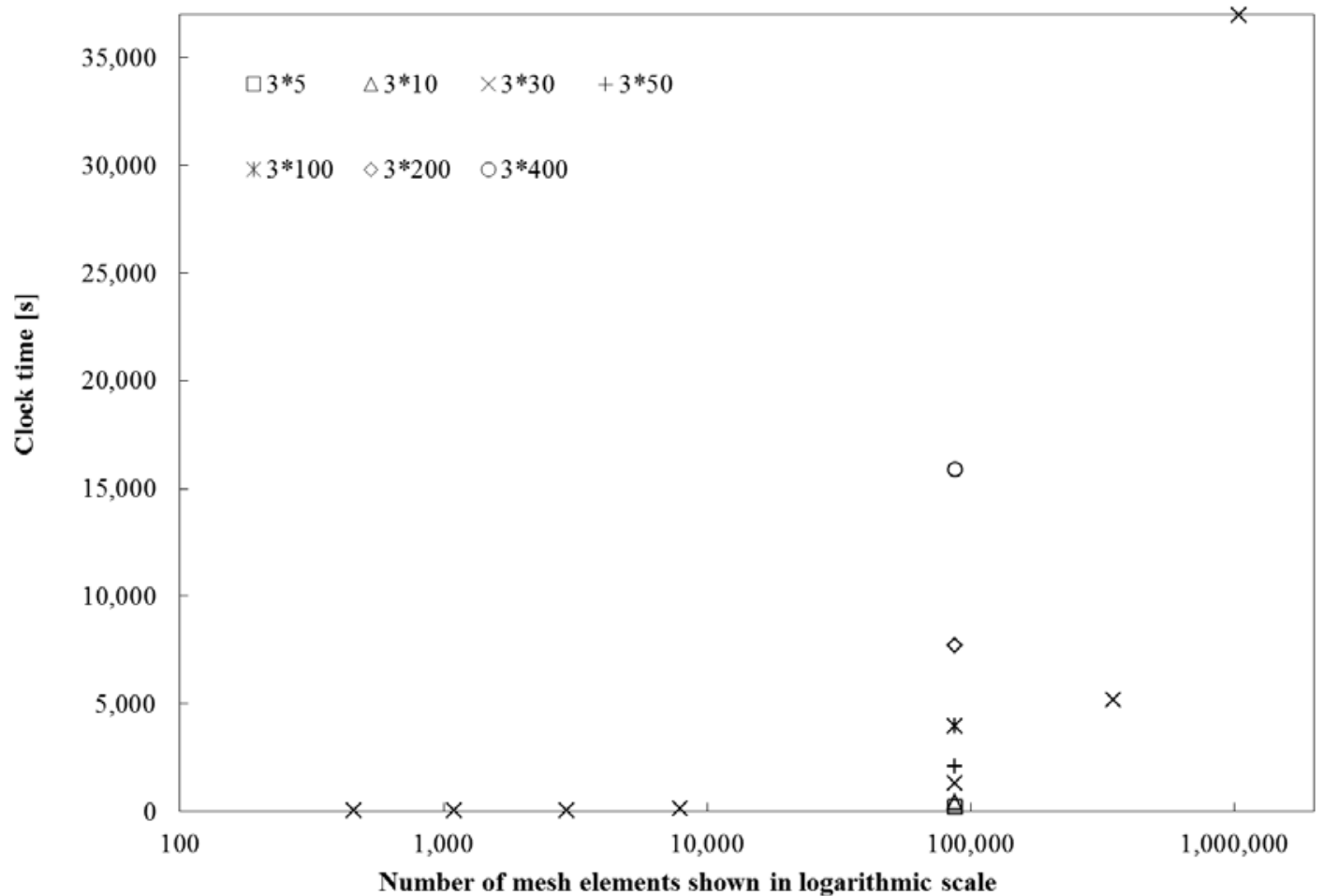

b)

Figure 9: a) Average absorbed heat flux $\left[\mathrm{W} / \mathrm{m}^{2}\right]$, b) Computational cost in clock time versus mesh count for various angular discretisation settings 
obtained by mesh refinement. In other words, when using second-order upwind discretisation for DO, refining the control angles has a much larger effect than refining the mesh. The reason for this was discussed in Section 2.2, i.e. the ray effect error is reduced by increasing the angular discretisation while refining the mesh only removes the false scattering error, which is already reduced by the second-order discretisation of the DO equations.

2. When the mesh number is increased beyond a certain count, there is a dramatic increase in computational cost because of the $4 \times N_{\theta} \times N_{\phi}$ equations that are being solved on the mesh (Figure 9b). As can be seen from the angular discretisation variation at a mesh count of 86,725 , the same dramatic increase occurs for larger $N_{\phi}$ values. The asymptotic behaviour of the heat flux value above a count of 100,000 cells (Figure 9a) confirms that this mesh gives an independent result.

Based on the above, the suggested method of conducting a mesh and angular discretisation study is to first conduct a mesh independence study of the coarsest control angle. After determining a suitable and converged mesh, then conduct an angular discretisation study and try to refine the control angles as much as is feasible.

\subsubsection{ANSYS Fluent results versus SolTrace results}

Before the ANSYS Fluent results are compared with the SolTrace results, the advantages and disadvantages of modelling in ANSYS Fluent are compared with SolTrace modelling. As discussed before, modelling glass poses two interesting challenges, namely capturing the greenhouse effect and modelling the refraction of rays. The simulation of the former is harder or sometimes impossible (e.g. dual-band effects on rays) in SolTrace while the definition of the latter is possible in both SolTrace and ANSYS Fluent. To capture ray refractions correctly in SolTrace, two separate surfaces located a finite distance (equal the glass thickness) from each other have to be defined with a semi-transparent definition. Therefore, defining glass as a solid medium and capturing its refraction are easier in ANSYS Fluent. The possibility of easily defining multiple wavelength bands in Fluent makes it trivial to model the greenhouse effect. The higher computational cost of ANSYS Fluent compared to SolTrace is offset by the fact that as a full-featured CFD code, it also allows for the modelling of fluid flow and conjugate heat transfer within the same environment. The higher computational cost of ANSYS Fluent compared to SolTrace is offset by the fact that as a full-featured CFD code, it also allows for the modelling of fluid flow and conjugate heat transfer within the same environment.

To compare the results of ANSYS Fluent and SolTrace, the glass absorption (as defined in Table 5) was neglected in the ANSYS Fluent simulation to allow for a direct comparison with SolTrace. This means that the absorbed flux on the pipes is higher (by about 20\%) than the values listed in Table 8. Table 9 lists the average circumferential heat flux of the 3rd and 4th pipes as well as the total average flux. It can be seen that there is excellent agreement between ANSYS Fluent and SolTrace, although enhanced by a fine mesh (346,900 cells) and a high DO setting (3x200). One million desired rays were used for SolTrace. The heat flux distributions are compared in the radar plots of Figure 10, again for the same settings. It can be seen that the 


\begin{tabular}{|c|c|c|c|c|}
\hline \multicolumn{5}{|c|}{ Table 9: Comparison of ANSYS Fluent and SolTrace heat flux } \\
\hline Method & $\begin{array}{c}\text { Area-weighted } \\
\text { average of } \\
\text { absorbed heat flux } \\
\text { on the } 0.0375 \\
\text { distance from } \\
\text { centre (average of } \\
\text { pipe } 2 \& 3)\left[\mathrm{W} / \mathrm{m}^{2}\right]\end{array}$ & $\begin{array}{l}\text { Area-weighted } \\
\text { average of } \\
\text { absorbed heat } \\
\text { flux on the } \\
0.1125 \text { distance } \\
\text { from centre } \\
\text { (average of pipe } \\
\text { 1\&4) [W/m²] }\end{array}$ & $\begin{array}{c}\text { Average } \\
\text { of all } \\
\text { pipes } \\
{\left[\mathrm{W} / \mathbf{m}^{2}\right]}\end{array}$ & $\begin{array}{c}\text { Deviation } \\
\text { percentage of } \\
\text { ANSYS FLUENT } \\
\text { result for all pipes } \\
\text { from SolTrace } \\
\text { result }(\%)\end{array}$ \\
\hline $\begin{array}{c}\text { FV without glass } \\
\text { absorption (347k mesh, } \\
\text { 3*200 DO) }\end{array}$ & 11,021 & 11,671 & 11,346 & -0.22 \\
\hline Ray tracing (1e6 rays) & 10,949 & 11,794 & 11,371 & 0 \\
\hline
\end{tabular}




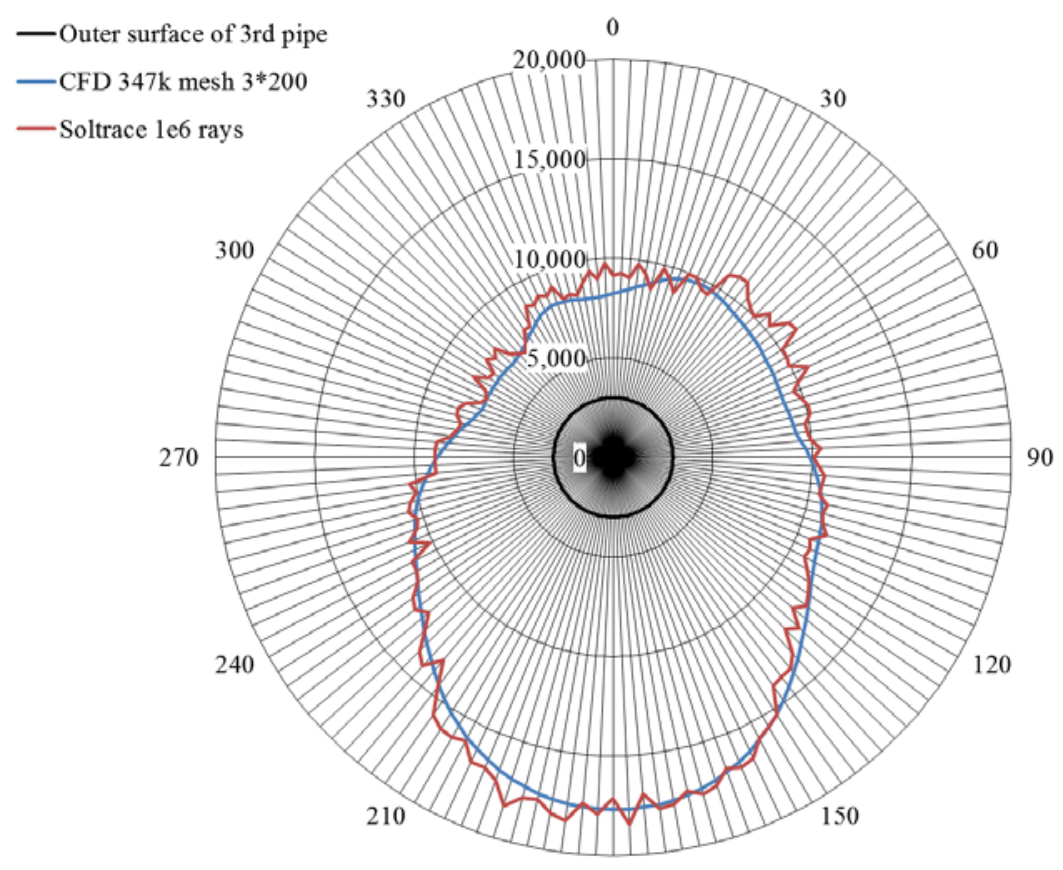

180

a) $3^{\text {rd }}$ pipe distribution

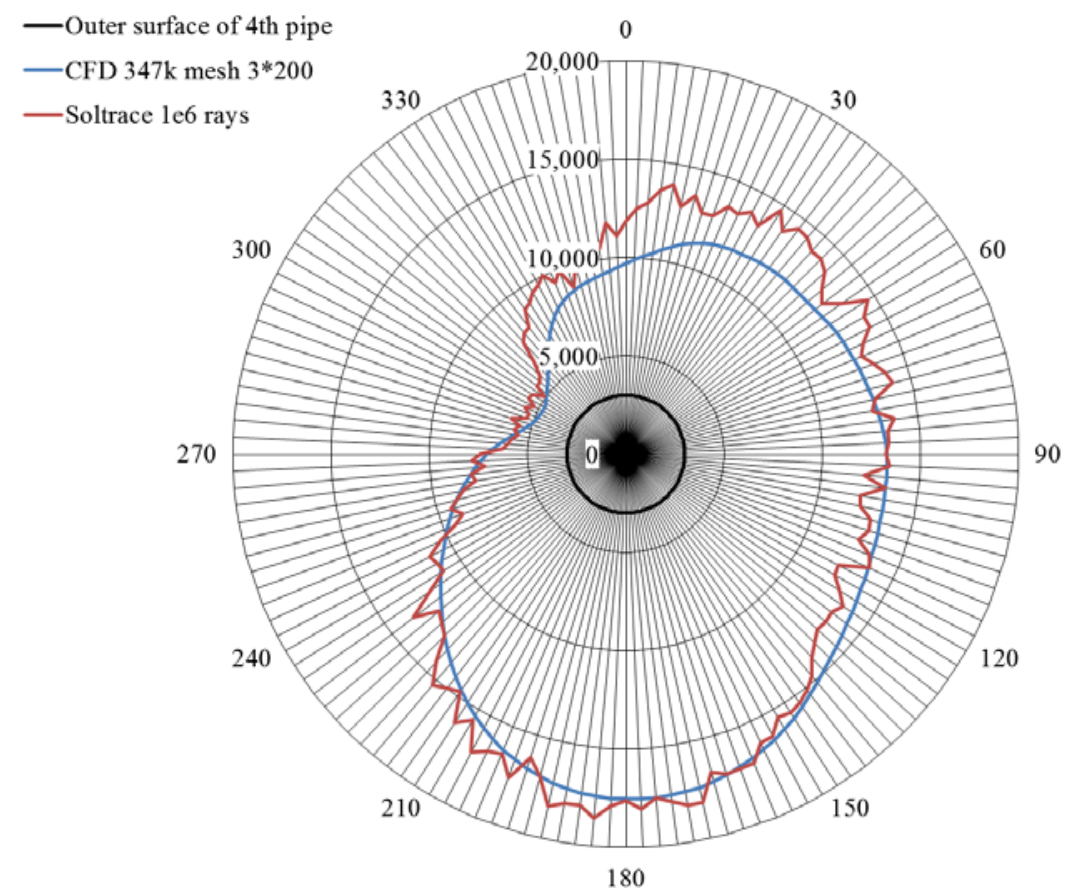

b) $4^{\text {th }}$ pipe distribution

Figure 10: Radar plots of heat flux distribution $\left[\mathrm{W} / \mathrm{m}^{2}\right]$ around absorber pipes between CFD (mesh 346,900 cells, $3 * 200$ DO) and SolTrace (1 million rays) 


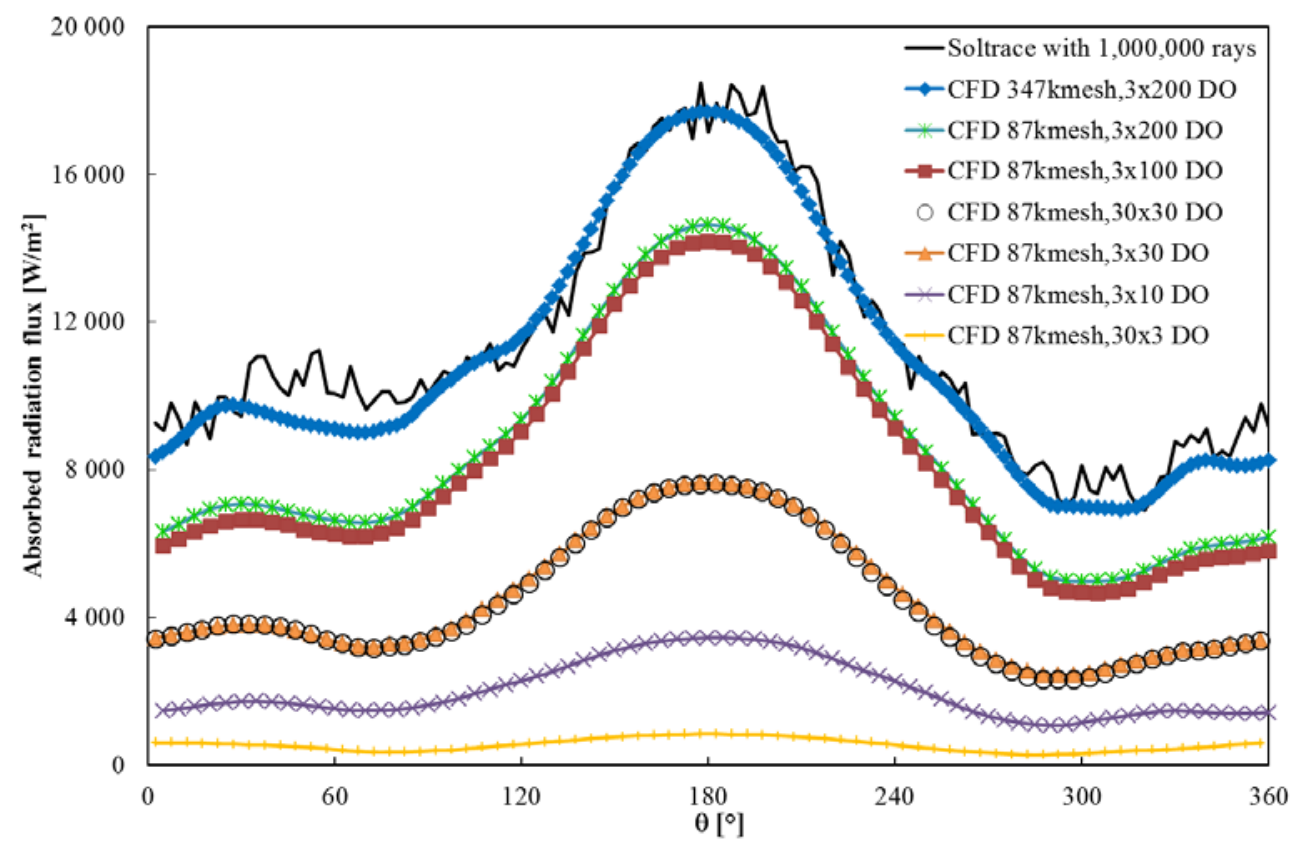

a)

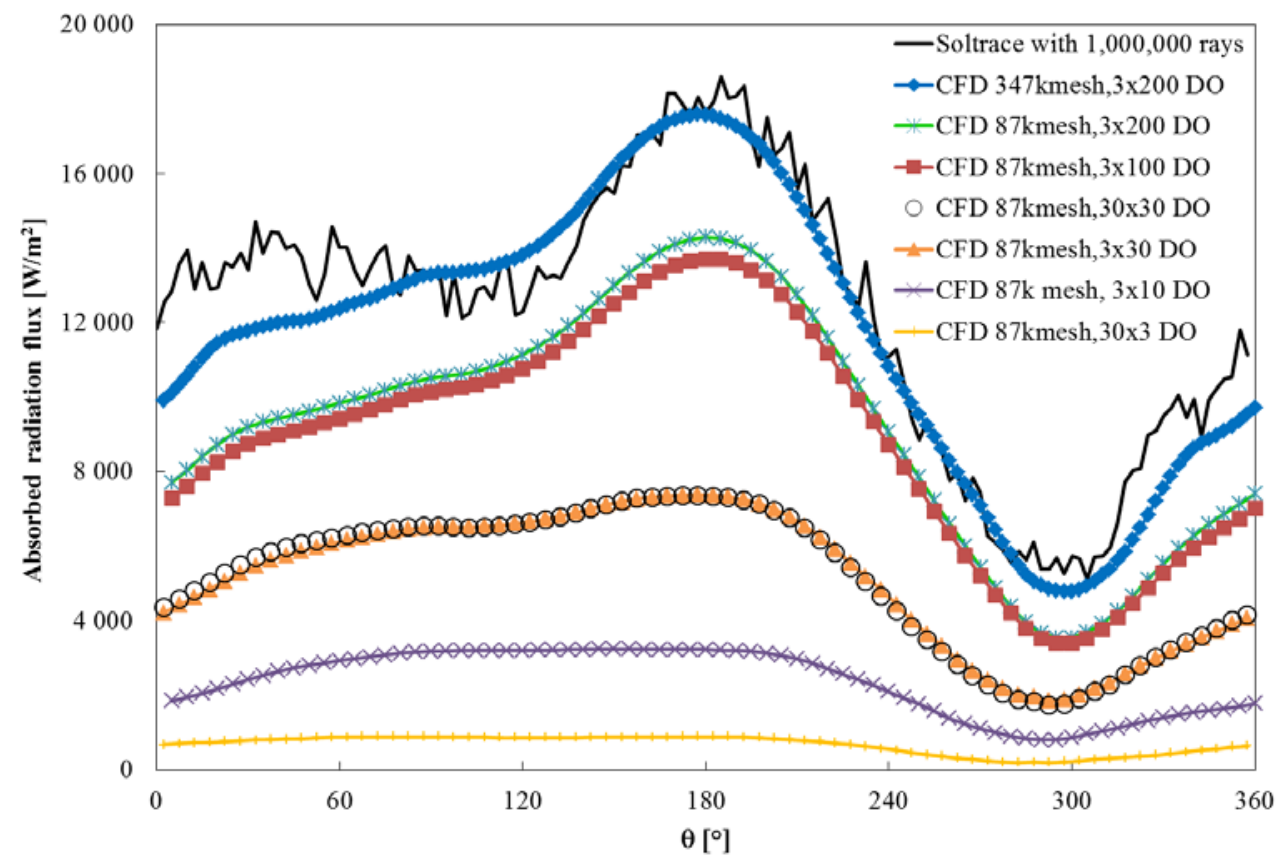

b)

Figure 11: Comparison of heat flux distribution [W/ $\left./ \mathrm{m}^{2}\right]$ around absorber pipes for different CFD settings and SolTrace (1 million rays) a) 3rd pipe, b) 4th pipe 
distributions are also in excellent agreement, providing confidence that the FV method can accurately predict non-uniform heat flux distributions, albeit at a higher cost. As before, the maximum heat flux occurs on the lower part of the pipes facing the mirrors with the lowest flux on the top side of the pipe. The slight asymmetry in the top left quadrant of the 3rd pipe (Figure 10a) is caused by blocking and shading of the adjacent pipe. The 4th pipe again displays an interesting phenomenon around $0^{\circ}$ to $60^{\circ}$. There is an asymmetry in the distribution caused by the proximity of the inclined cavity wall and its junction with the top wall of the cavity. Interestingly, this is the only region where the ANSYS Fluent and SolTrace results do not fall on top of each other. Remember that this was also the region in Figure 6b where the result only stabilised after the ray count was increased to 1 million and above.

To illustrate how the ray effect and false scattering are reduced for this more realistic application than that described in Section 2.2 (with a more complex geometry and a subtended sun beam angle instead of collimated light), Figure 11 displays the results for various mesh and DO settings as compared with the SolTrace result in a heat flux versus circumferential angle plot. For a relatively coarse main control angle $(\varphi)$ of 10 (shown as the $\left(3^{*} 10\right)$ case), the flux value is much lower than it should be, although the distribution has the correct shape. This can be attributed to both a ray effect and a false scattering (diffusion) error. The effect of refining the control angle $(3 * 30,3 * 100$ and $3 * 200)$ is to reduce the ray effect but not necessarily false scattering. Figure 11 shows that the shape of the absorbed radiation profile remains constant when the control angle settings of the 86,725 mesh case are changed from $3 * 100$ to $3 * 200$. The false scattering effect is only removed when the mesh is further refined to 346,900 cells. Note that the false scattering effect has contributions from the whole computational domain, including the region of the reflecting mirrors. Therefore, the complexity of the modelled geometry makes it difficult to isolate individual error contributions.

Figure 11 also includes a comparison at one mesh $(86,725)$ resolution of the correct selection of control angle discretization for a planar 2-D geometry. It can be seen that the $30 * 30$ and $3 * 30$ cases give essentially the same result, while the $30 * 3$ setting heavily underestimates the correct distribution. This same trend was confirmed in section 2.2 for the simple test case and holds true for the complex, but still 2-D, geometry considered here. In summary, if the 2-D computational mesh is correctly aligned with the global coordinate system, one of the two discrete ordinate directions need only be discretized with 3 divisions, thereby saving on computational expense. The number of divisions in the other ordinate direction should however be as fine as computational resources allow.

It is of course important to capture the shape and correct value of the heat flux distribution, especially when an accurate thermal evaluation of the cavity is required. The severity of the nonuniformity of the heat flux distribution is also important to capture as it would lead to nonuniformity in the pipe temperature distribution, which could lead to undesirable thermal expansion and thermal stresses.

And last but not least, the incident radiation contours for the 346,900 mesh and 3*200 angular discretisation are shown in Figure 12. The maximum contour display value in this figure was set 


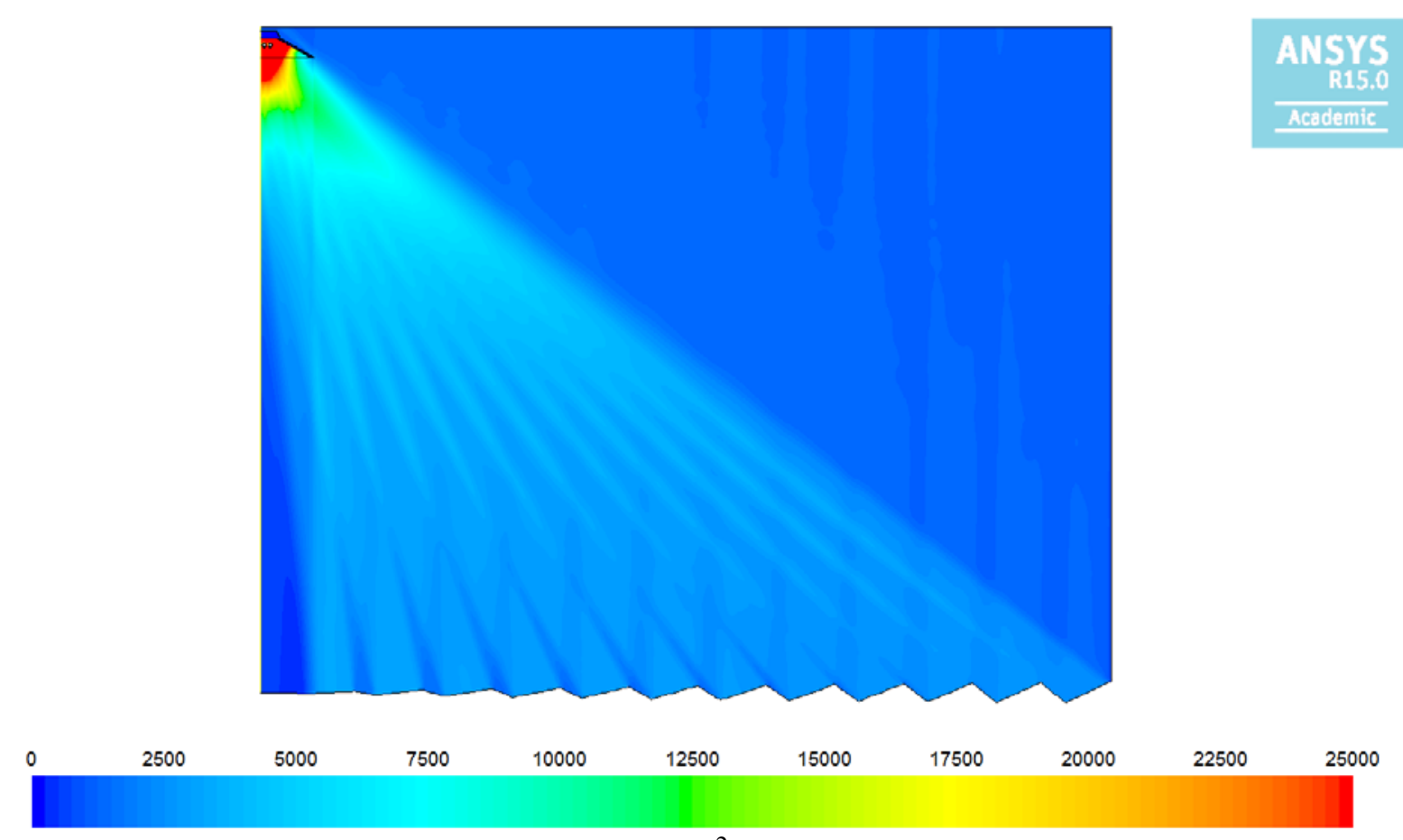

Figure 12: Contours of incident radiation $\left[\mathrm{W} / \mathrm{m}^{2}\right]$ in the LFC domain for 346,900 mesh and 3x200 angular discretisations 
to $25,000\left(\mathrm{~W} / \mathrm{m}^{2}\right)$ instead of the global calculated value of $45,907\left(\mathrm{~W} / \mathrm{m}^{2}\right)$ to highlight the optical effects of blocking and shading of adjacent mirrors as well as the concentration effect at the receiver.

\section{LFC cavity thermal modelling in ANSYS Fluent}

The ability of ANSYS Fluent to model the thermal characteristics of a cavity receiver is well known (e.g. Cheng et al., 2012; Martinek and Weimer, 2013; Lin et al., 2013; He et al., 2011). In most cases, a separate code was used for the optical modelling of the solar field, resulting in interface definitions and linking issues. In this section, the authors introduce an approach that uses ANSYS FLUENT features for the integration of the optical and thermal modelling in a single software domain, that of ANSYS Workbench. Because of this integration and the availability of parameters and design optimisation tools within this environment, the extension to conducting optimisation studies based on the optical and thermal modelling described in this paper is straightforward.

The following section describes the thermal model of the LFC cavity using ANSYS Fluent. This model incorporates the non-uniform heat flux distribution described above. To validate the suggested phased approach, a full 3-D optical and thermal model is run for comparison.

\subsection{3-D thermal geometry and meshing}

The non-uniform heat flux determined by either a ray-tracing code or an FV implementation of the RTE needs to be included in the conjugate heat transfer model of the cavity receiver for the thermal efficiency of the cavity to be calculated. Since the external surfaces of the pipes are internal surfaces in a CFD model of the cavity, it is not possible to apply the heat source as a standard boundary condition profile. This means that the heat flux must be converted to an internal volumetric heat source. Cheng at al. (2012) and He et al. (2011) treat the volumetric heat source as a surface phenomenon because of the fact that the absorption occurs very close to the surface (within $1 \mu \mathrm{m}$, according to Bergman et al. (2011)). To mimic this surface/volumetric interaction, the current study applies a volumetric heat source to a very thin shell region of each pipe $\left(1 / 10^{\text {th }}\right.$ of the pipe thickness).

For the thermal modelling of an LFC, a 3-D model of trapezoidal cavity was created in ANSYS Workbench (ANSYS, 2013c) and meshed in ANSYS Meshing tool based on the parameters defined in Table 2. The symmetrical 3-D CFD model and meshes are displayed in Figure 13. The thin shell for the application of the volumetric heat source is indicated in Figure 13b.

Figure 13a shows that a symmetrical half of the cavity is considered with insulation on top and on the sides. The aperture is again covered by a glass cover. The external faces of these solids are now boundary conditions in this model. It can be seen that the cavity is extruded in the heat transfer fluid (HTF) flow direction by only a small distance $(1 \mathrm{~cm})$. This is justified by using fully developed flow profiles for the HTF and is based on a sensitivity study that indicated that five computational cells in the flow direction were sufficient to capture the effects of the third dimension. The HTF considered is single-phase liquid water. The HTF domain was subdivided 


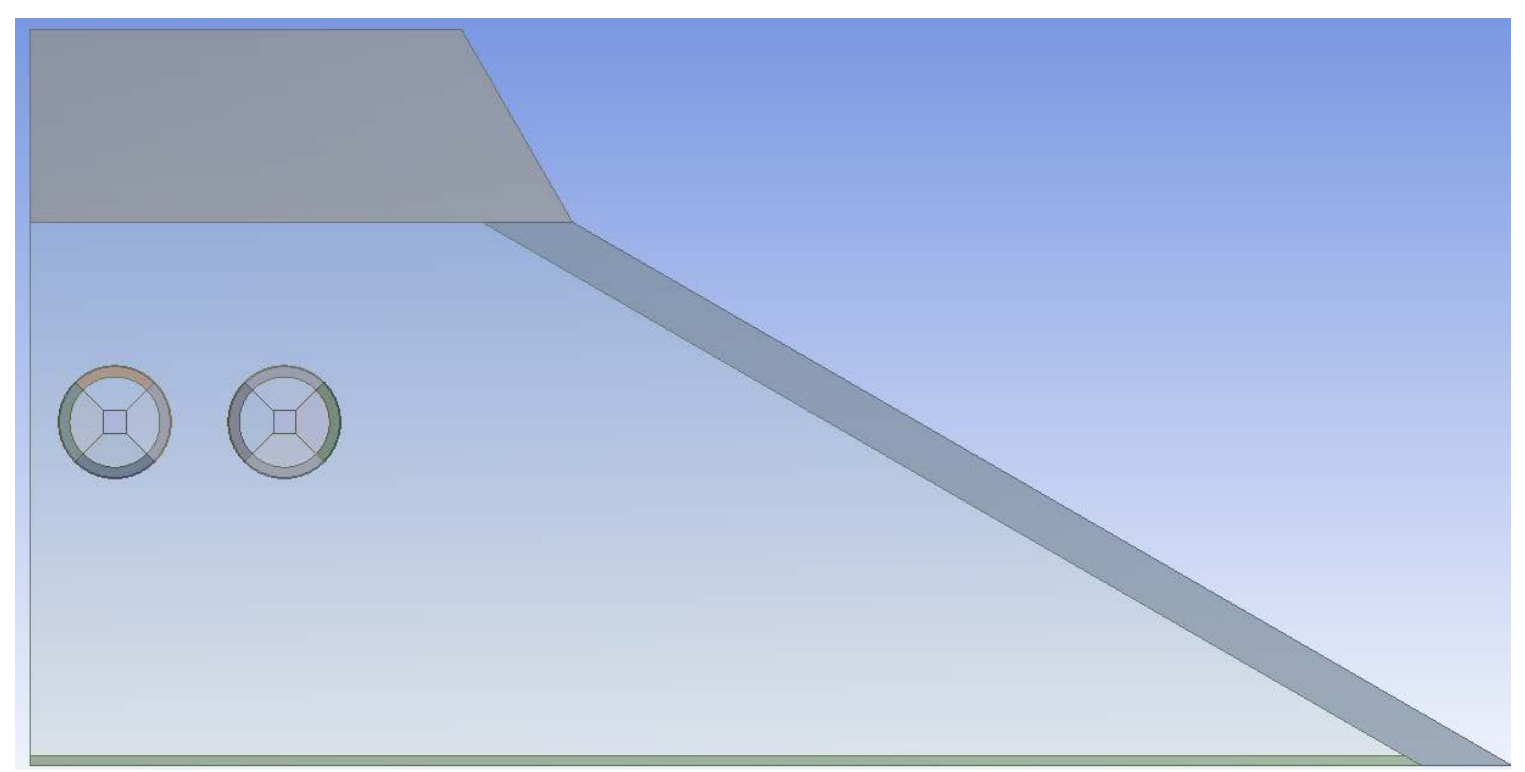

(a)

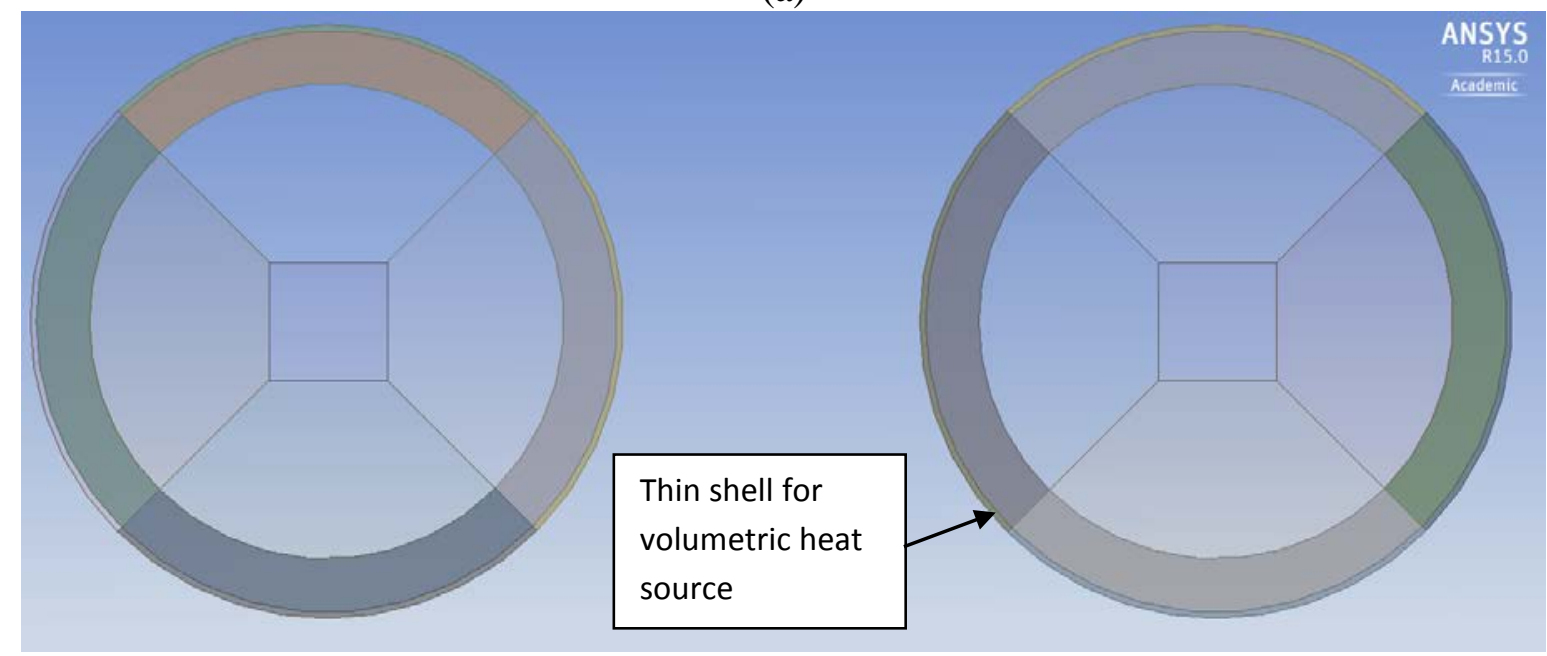

(b)

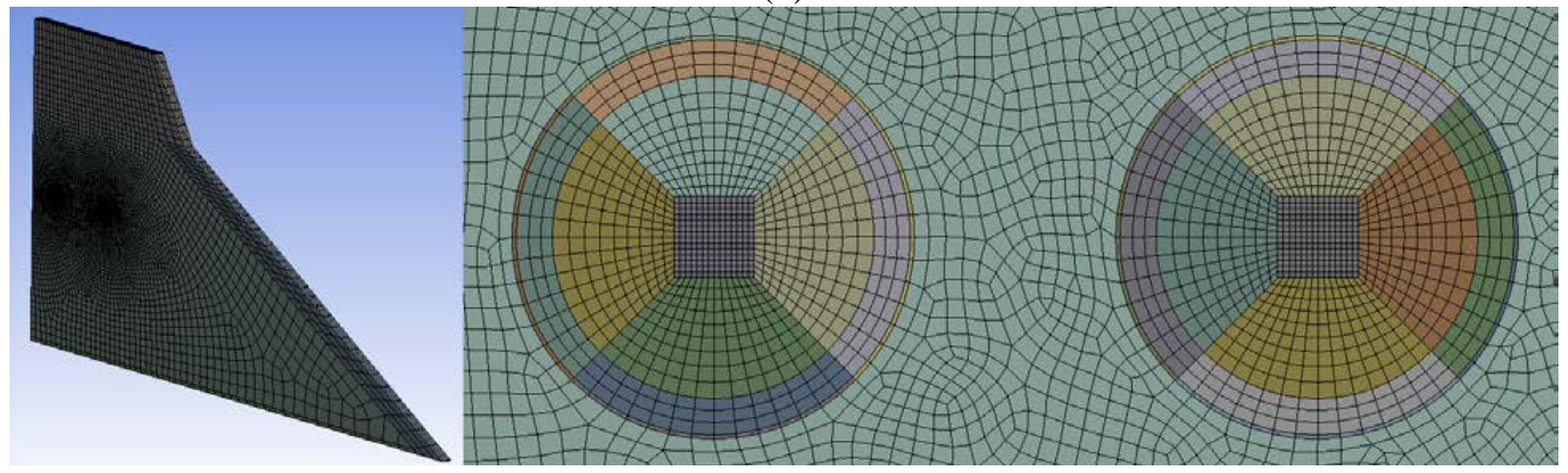

(c)

Figure 13: (a) Entire thermal domain, (b) Zoom of pipes, (c) Mesh on entire thermal domain and zoom area 
to allow for mapped (quadrilateral) meshing (Figure 13b) for increased accuracy and faster convergence of the turbulent flow. The rest of the cavity fluid was paved with quad/tri elements whereas the insulation, glass and pipes had mapped meshes. After generating the mesh of the cavity cross-section, a swept mesh (or Cooper mesh) was considered along the z-direction (left part of Figure 13c). The volumetric heat source in the outer shell of each pipe would conduct through the inner section of each pipe towards the HTF and also interact with the air in the cavity and other cavity surfaces through convection and radiation.

\subsection{Boundary conditions and material properties of 3-D thermal modelling}

As mentioned above, fully developed profiles are used for the HTF inlet. These include the three velocity components and the turbulent kinetic energy and turbulence dissipation rate. A UserDefined Function (UDF) was used to define these boundary conditions, based on the following: The velocity profile is based on the $1 / 7^{\text {th }}$ power law (Schlichting, 1979):

$$
\frac{V_{z}}{V_{\text {centerline }}}=\left(1-\frac{r}{R}\right)^{\frac{1}{7}}
$$

where $V_{\text {cenererine }}$ is the free-stream velocity, which is calculated by the average velocity across the pipe, $R$ is the inner radius of the pipe and $v_{z}$ is the $z$-velocity at a distance $r$ from the pipe centre.

For defining the turbulent kinetic energy and the turbulence dissipation rate, the wall shear stress must be determined. Using the power law above would result in a very high velocity gradient at the wall and would therefore lead to an unrealistic wall shear stress and friction velocity. Hence, Blasius's law of friction is used for the wall shear stress (Schlichting, 1979), valid for a range of Reynolds numbers based on diameter of 4,000 to 1e5 (White, 2006):

$\frac{\tau_{w}}{\rho}=0.03955 \times V_{\text {average }}^{2} \times\left(\frac{\rho V_{\text {average }} R}{\mu}\right)^{\frac{-1}{4}}$

A Reynolds number of about 5,000 is used in the current study. For an average or mean velocity that is $80 \%$ of the centre line velocity (Schlichting, 1979), equation (2) becomes

$$
\frac{\tau_{w}}{\rho}=0.0225 \times V_{\text {centerline }}^{2} \times\left(\frac{\rho V_{\text {centerline }} R}{\mu}\right)^{\frac{-1}{4}}=v_{\tau}^{2}
$$

where $v_{\tau}$ is the friction velocity.

The turbulent kinetic energy at the wall (obeying the log law) follows from the friction velocity (White, 2006):

$k_{\text {near }- \text { wall }}=\frac{v_{\tau}{ }^{2}}{\sqrt{C_{\mu}}}$

and is assumed to vary linearly from this value to its free-stream value (ANSYS, 2006): 
$k_{\text {free_stream }}=0.002 V_{\text {centerline }}^{2}$

The turbulence dissipation rate is related to the friction velocity (White, 2006):

$\varepsilon=\frac{v_{\tau}^{3}}{l}$

where $l$ is a mixing length. Hence

$$
\varepsilon=\frac{C_{\mu}^{3 / 4}\left(k^{3 / 2}\right)}{l}
$$

where the mixing length $l$ is the minimum $0.041(R-r)$ and $0.085 R$ (ANSYS, 2006).

For referral purposes, the plane at $\mathrm{z}=0$ is called the In-plane, $\mathrm{z}=1$ the Out-plane (except for the pipe outlets) and $x=0$ (centre line) is called the Mid-plane.

In this study, an approaching wind was considered so that both convective and radiative thermal boundary conditions had to be applied to external boundaries of the cavity domain. The assumption of external forced convection (wind effect) was simulated by a constant convective surface heat transfer coefficient while the radiation assumption was implemented by a surface emissivity and reference temperature (sky temperature for the top and side walls and LFC mirror temperature, assumed to be $5 \mathrm{~K}$ higher than ambient (Pye, 2008)), for the lower cavity surfaces.

The glass properties were described in previous sections, but the 3-D thermal model uses a dualband approach (Moghimi et al., 2014, 2015). A dual-band absorption coefficient is defined in ANSYS Fluent; according to Beer-Lambert's law for a $3.25 \mathrm{~mm}$ glass thickness, the glass absorption coefficient values should be converted to $29 \%$ and $99 \%$ absorption of wavelengths below and above $4.25 \mu \mathrm{m}$, the implemented cut-off wavelength. Consequently, glass is defined to be almost opaque to the higher wavelength band (above $4.25 \mu \mathrm{m}$ ), while it is almost semitransparent in the lower wavelength band (below $4.25 \mu \mathrm{m}$ ). The result is that the re-radiated energy from the cavity surfaces will be absorbed by the glass because of the spectral shift in emissive power of lower temperature surfaces due to Planck's law.

Last but not least, the reflected energy from a surface depends on the surface roughness, and can be reflected either specularly (in one direction as for a mirror), diffusely (in all directions) or in some combination of the two. In radiation terminology, a rough surface is a surface that has a roughness height that is much larger than the incident radiation wavelength. In other words, if the root mean square (RMS) of the surface roughness is much higher than the incident radiation wavelength, the surface acts as diffuse, and if it was much lower it acts as specular. When the radiation wavelength is of similar magnitude to the roughness height, the reflection is of a mixed nature between specular and diffuse. In ANSYS Fluent this behaviour is controlled by using a diffuse fraction between 0 and 1 . It is noteworthy that both types of reflections have the same amount of total energy implying that the diffuse reflection in any direction is less than the corresponding total specular amount.

Based on the above discussion, the material properties and boundary conditions are tabulated in Tables 10 and 11, respectively. 


\begin{tabular}{|c|c|c|c|c|}
\hline \multicolumn{5}{|c|}{ Table 10: Material properties of thermal domain of 3-D model } \\
\hline Material & Density $\left[\mathrm{kg} / \mathrm{m}^{3}\right]$ & $\begin{array}{c}\text { Specific heat } \\
{[\mathrm{J} / \mathrm{kg}-\mathrm{K}]}\end{array}$ & $\begin{array}{c}\text { Thermal } \\
\text { conductivity } \\
\text { [W/m-K] }\end{array}$ & Other \\
\hline Air in cavity & $\begin{array}{l}\text { Incompressible } \\
\text { ideal gas }\end{array}$ & $\begin{array}{l}\text { Piecewise linear } \\
\text { function of } \\
\text { temperature }\end{array}$ & $\begin{array}{l}\text { Piecewise linear } \\
\text { function of } \\
\text { temperature }\end{array}$ & $\begin{array}{l}\text { Viscosity [Pa.s]: Piecewise } \\
\text { linear function of } \\
\text { temperature, Participating } \\
\text { in radiation }\end{array}$ \\
\hline Glass & 2,650 & 786 & 1.5 & $\begin{array}{c}\text { Refractive index }=1.5, \\
\text { absorption coefficient }\left[\mathrm{m}^{-1}\right] \\
=2,300 \\
\text {, Participating in radiation }\end{array}$ \\
\hline HTF-water & 998 & 4,182 & 0.6 & Viscosity $[$ Pa.s $]=0.001003$ \\
\hline $\begin{array}{l}\text { Insulation-glass wool } \\
\text { (TIASA, 2001) }\end{array}$ & 48 & 446 & $\begin{array}{l}\text { Piecewise linear } \\
\text { function of } \\
\text { temperature } \\
\end{array}$ & - \\
\hline Pipe-carbon steel & 7,818 & 670 & 54 & - \\
\hline
\end{tabular}




\begin{tabular}{|c|c|c|c|c|c|c|}
\hline Surface & BC type & $\begin{array}{c}\begin{array}{c}\text { Velocity } \\
\text { compon } \\
\text { ents } \\
{[\mathrm{m} / \mathrm{s}]}\end{array} \\
\end{array}$ & $\begin{array}{c}\text { Temperature } \\
{[\mathrm{K}]}\end{array}$ & 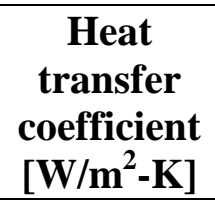 & Emissivity & Other \\
\hline Pipe inner side & $\begin{array}{l}\text { Stationary wall and coupled } \\
\text { thermal condition }\end{array}$ & 0,0 & - & 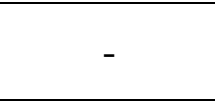 & - & - \\
\hline Pipe outer side & $\begin{array}{c}\text { Stationary wall and opaque } \\
\text { with selective absorber } \\
\text { coating and coupled thermal } \\
\text { condition }\end{array}$ & 0,0 & - & - & $\begin{array}{c}\text { Band0=0.95, } \\
\text { Band } 1=0.1 \\
\text { (Kennedy, } \\
\text { 2002) }\end{array}$ & $\begin{array}{l}\text { Diffuse Fraction: } \\
\text { Band } 0=1, \\
\text { Band } 1=0\end{array}$ \\
\hline Top and side wall & $\begin{array}{l}\text { Stationary wall and opaque } \\
\text { with reflective coating and } \\
\text { coupled thermal condition }\end{array}$ & 0,0 & - & - & $\begin{array}{l}\text { Band } 0=0.05 \\
\text { Band } 1=0.05\end{array}$ & $\begin{array}{c}\text { Diffuse Fraction: } \\
\text { Band0=1, } \\
\text { Band1 }=0\end{array}$ \\
\hline Glass inner side & $\begin{array}{l}\text { Stationary wall, semi- } \\
\text { transparent and coupled } \\
\text { thermal condition }\end{array}$ & 0,0 & - & - & - & $\begin{array}{c}\text { Diffuse Fraction: } \\
\text { Band } 0=0, \\
\text { Band } 1=0\end{array}$ \\
\hline Glass outer side & Mixed thermal condition & - & $\begin{array}{c}300 \text { (conv), } \\
305 \text { (rad) } \\
\end{array}$ & 5 & 0.9 & - \\
\hline Insulation outer side & Mixed thermal condition & - & $\begin{array}{c}300 \text { (conv), } \\
\mathrm{T}_{\text {sky }}=0.0522^{*} \\
300^{1.5} \text { (rad) } \\
\end{array}$ & 5 & 0.75 & - \\
\hline Pipe inlet & $\begin{array}{c}\text { Fully developed turbulent } \\
\text { velocity inlet }\end{array}$ & UDF & 500 & - & - & $\begin{array}{c}\text { Equations (4), (5) } \\
\text { and (6) }\end{array}$ \\
\hline Pipe outlet & Outflow & - & - & - & - & - \\
\hline $\begin{array}{l}\text { In-plane, Out-plane, } \\
\text { Mid-plane }\end{array}$ & Symmetry & - & - & - & - & - \\
\hline
\end{tabular}




\subsection{Patching the non-uniform heat flux of optical domain in 3-D thermal domain}

The following procedure briefly describes the patching of the non-uniform heat flux (data taken from the 2-D optical domain) on the absorber pipes of the 3-D thermal domain as a volumetric heat source (for a more detailed procedure (Craig et al., 2010) refer to section 3 of the supplementary material):

1) Convert the absorbed radiation (solar load) on the pipes from the 2-D optical simulation into an interpolation file with the required 3-D Fluent format (*.ip).

2) Activate one user-defined scalar (UDS) and one user-defined memory location (UDM).

3) Initialise case and data.

4) Interpolate each individual source file to the corresponding UDS.

5) Copy UDS to UDM.

6) Link a source name to the UDM.

7) Assign source term to corresponding solid zone

8) Deactivate UDS.

After executing the procedure, the UDM data (containing the heat source) can be plotted as in Figure 14 to check the success of the patching operation. In other words, the non-uniform solar heat load was patched successfully for simulation in the thermal domain.

\subsection{CFD settings and mesh independence}

The realisable k- $\varepsilon$ turbulence model was considered for the HTF flow inside the pipes. The coupled scheme was selected to couple the pressure and velocity field for faster convergence of the results. For the thermal re-radiation, a second-order discretisation of the DO equations with an angular discretisation of $3 * 30$ with $3 * 3$ pixellation was used. As the mirror field is not included in this simulation, a cheaper DO implementation is possible. The settings for mesh generation on the cross-section of the thermal domain are the same as for the independent mesh settings in the optical domain in Section 2.3.3.3. Therefore, for the mesh independence study in 3-D, only the required number of cells along the z-direction was investigated. This study determined that five cells were sufficient for a mesh-independent result.

\subsection{3-D thermal results validation}

To validate the accuracy of the 2-D optical:3-D thermal approach, a full 3-D simulation was run, which incorporates both the 3-D mirror field and 3-D cavity thermal model with pipes and HTF. This model is more expensive to run because of the increased domain and solution of the RTE, energy and Navier-Stokes equations. However, it would not have any interpolation inaccuracies that may arise from the patching procedure. 

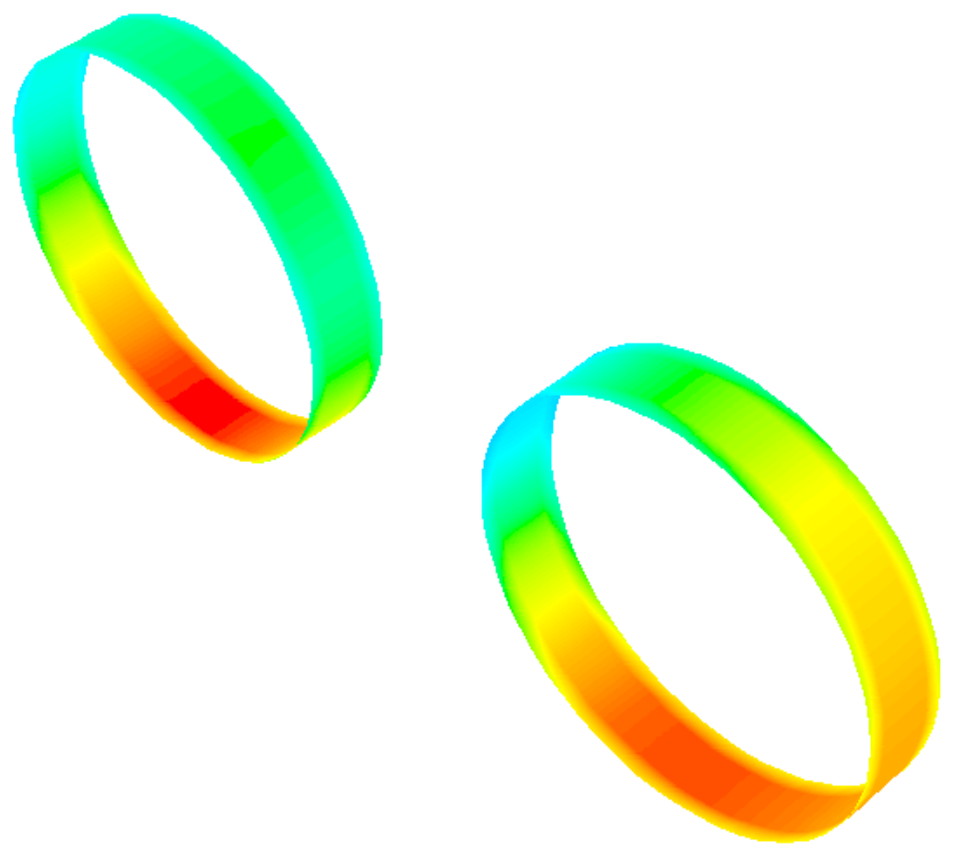

$0.000 \mathrm{e}+00 \quad 1.623 \mathrm{e}+06 \quad 3.246 \mathrm{e}+06 \quad 4.870 \mathrm{e}+06 \quad 6.493 \mathrm{e}+06 \quad 8.116 \mathrm{e}+06 \quad 9.739 \mathrm{e}+06 \quad 1.136 \mathrm{e}+07 \quad 1.299 \mathrm{e}+07 \quad 1.461 \mathrm{e}+07 \quad 1.623 \mathrm{e}+07 \quad 1.804 \mathrm{e}+07$

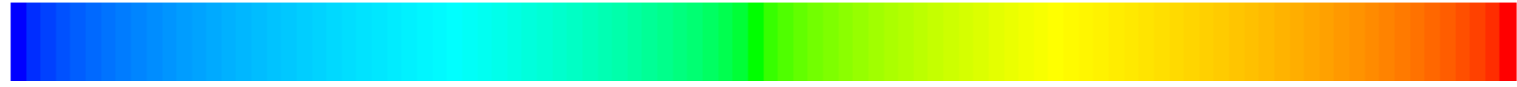

Figure 14: Contours of patching data (non-uniform solar heat flux for 346,900 mesh and 3x200 angular discretisations) as volumetric heat source $\left[\mathrm{W} / \mathrm{m}^{3}\right]$ in UDM 


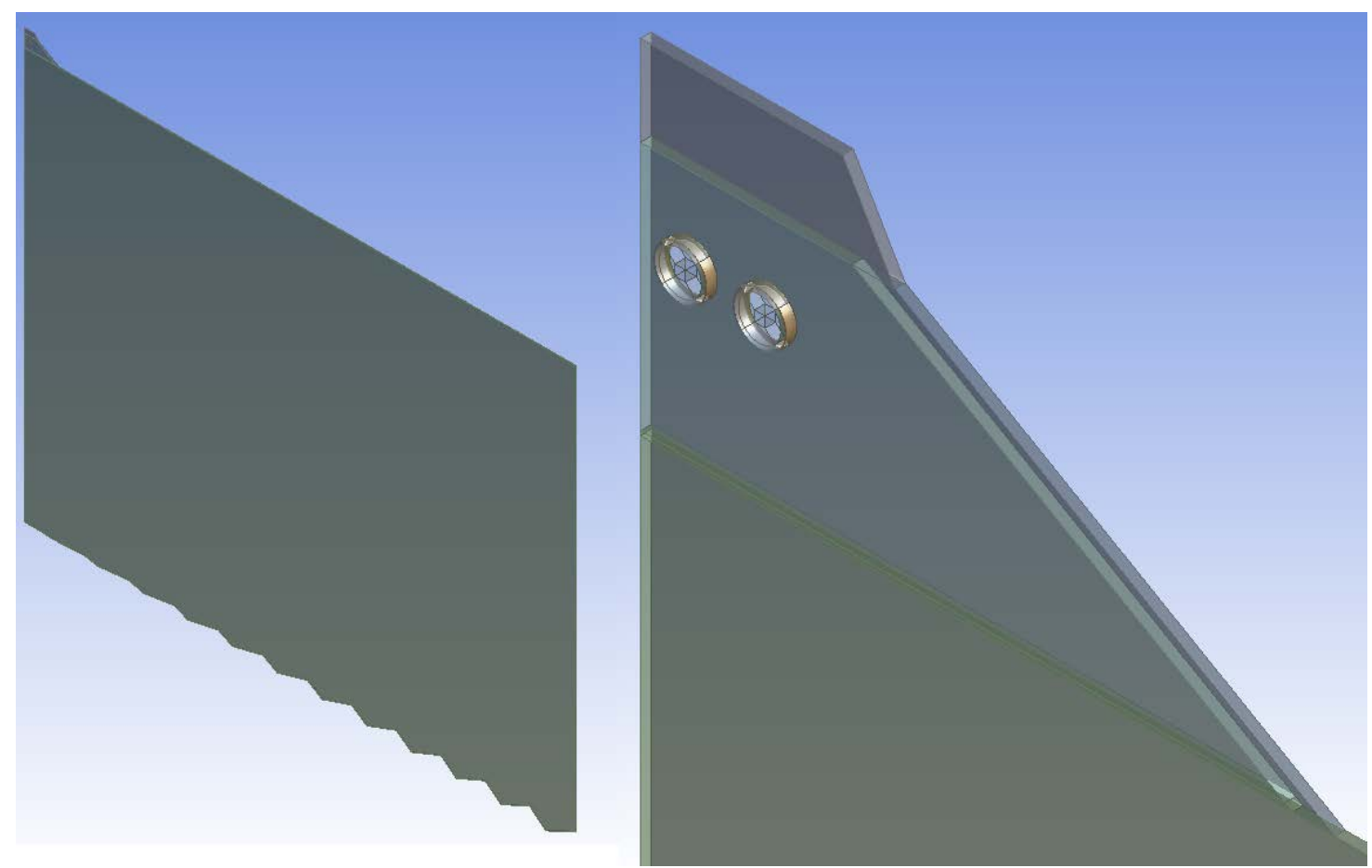

(a) Geometry of full 3-D domain with mirror field and close-up of 3-D cavity

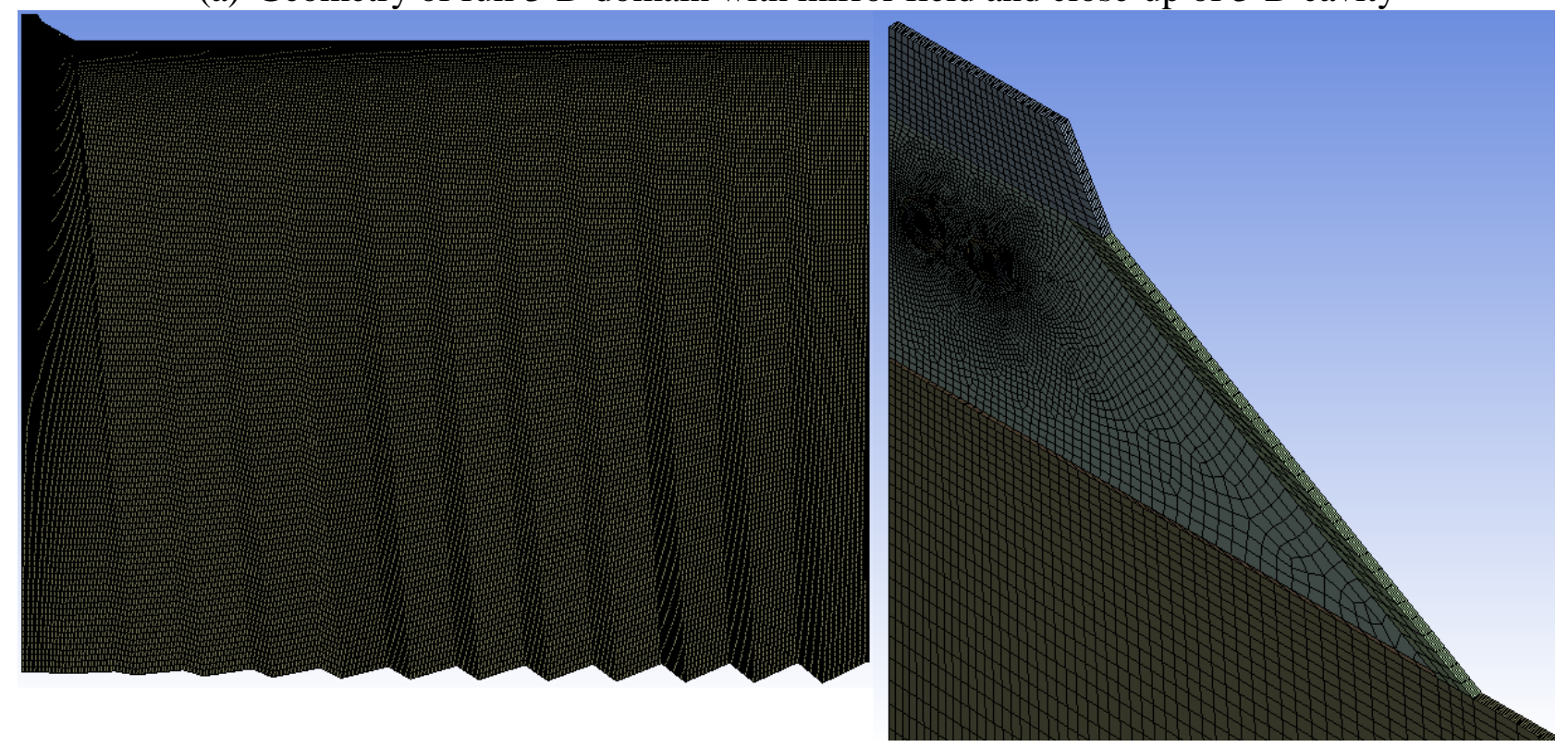

(b) Meshing of full 3-D domain and close-up of cavity

Figure 15: Geometry and mesh for full 3-D model 


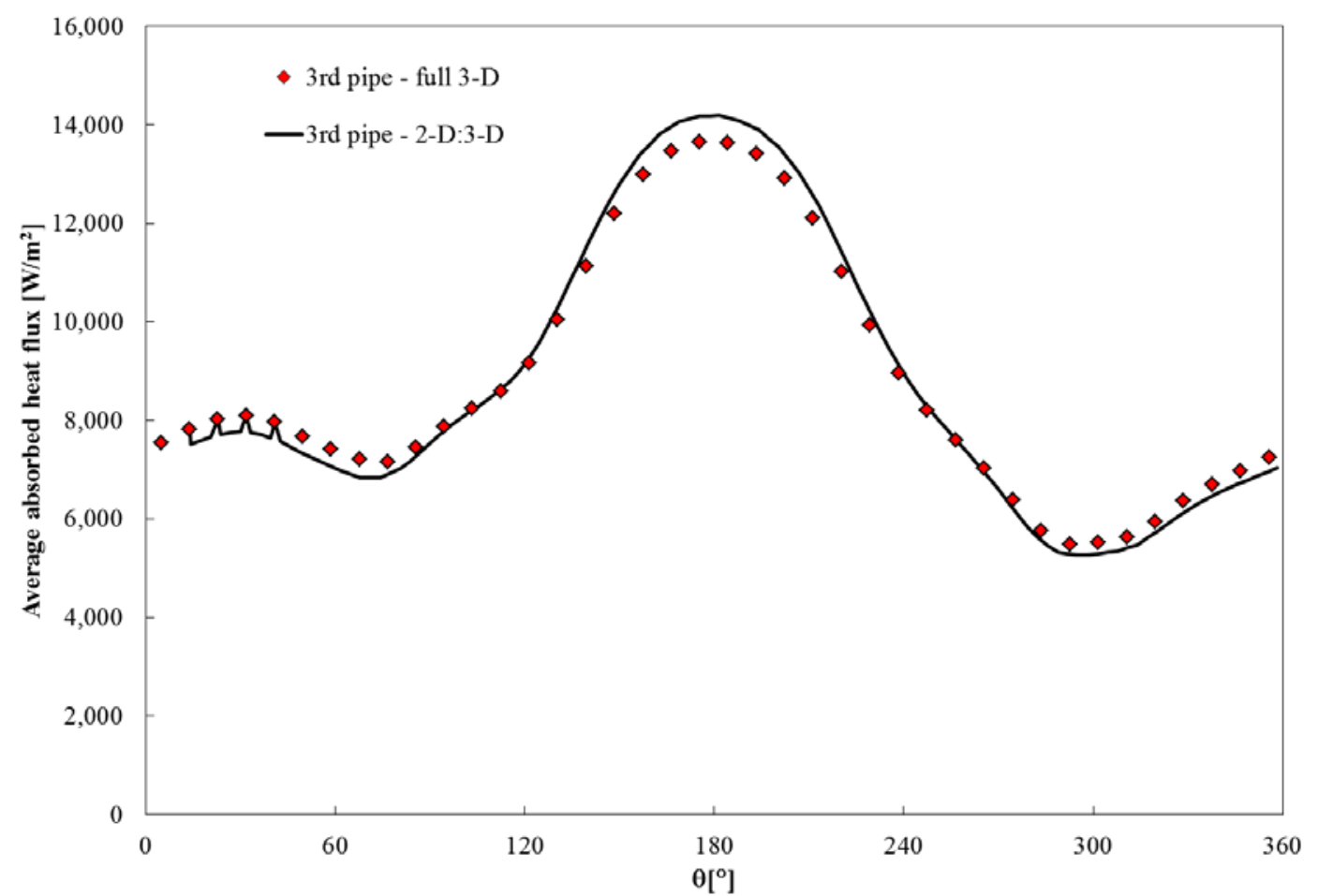

a)

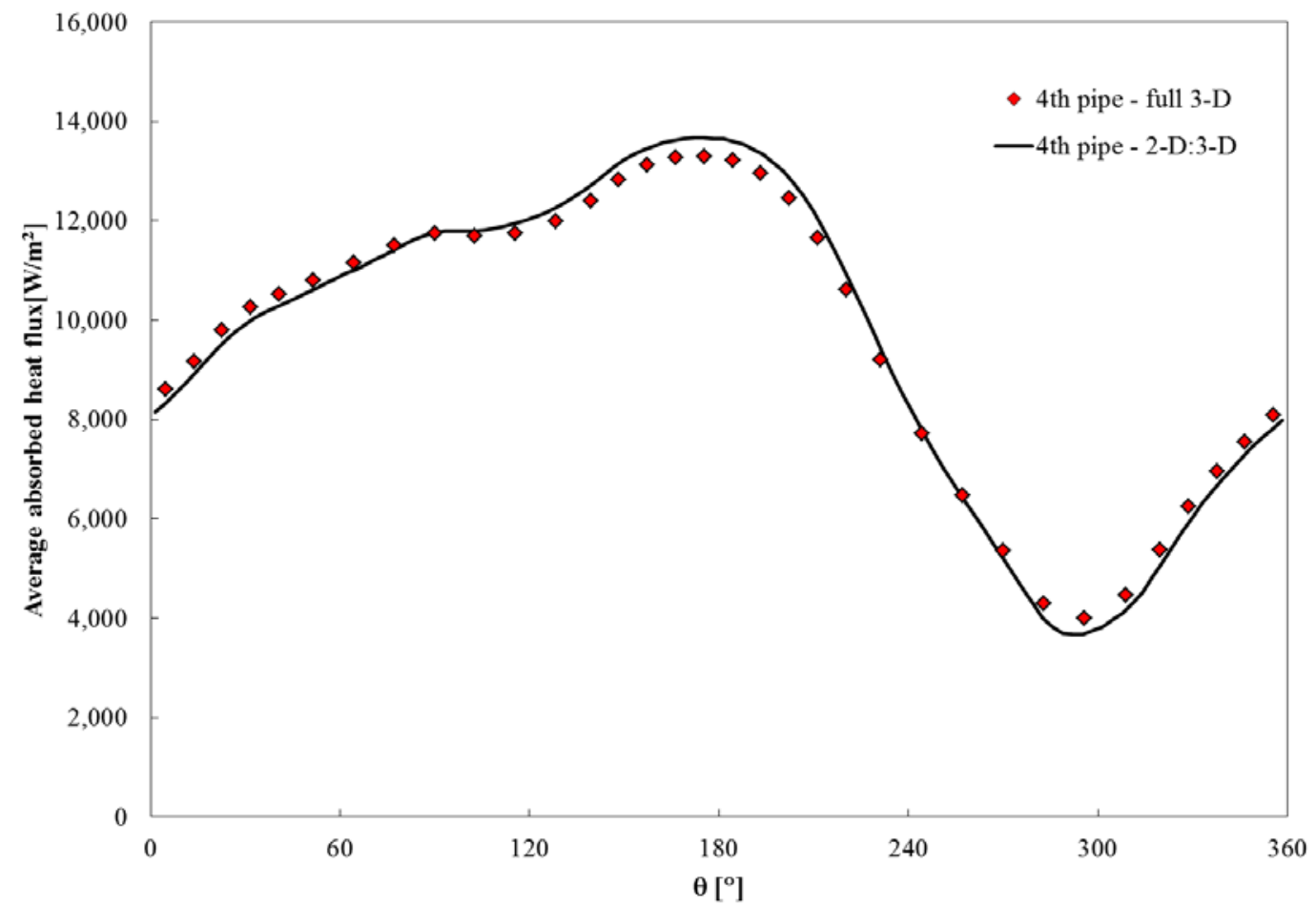

b)

Figure 16: Comparison of heat flux distribution $\left[\mathrm{W} / \mathrm{m}^{2}\right]$ around absorber pipes for 2-D:3-D and full 3-D models a) 3rd pipe, b) 4th pipe 


\begin{tabular}{|c|c|c|c|c|c|c|}
\hline \multicolumn{7}{|c|}{ Table 12: Comparison of 2-D optical:3-D thermal and full 3-D results } \\
\hline Idea & Pipe & Tin & Tout & $\begin{array}{l}\text { Mass } \\
\text { flow } \\
\text { rate }\end{array}$ & $\mathbf{C}_{\mathbf{p}}$ & $\begin{array}{c}\text { Total energy } \\
\text { transferred to } \\
\text { HTF }\end{array}$ \\
\hline \multirow{3}{*}{$\begin{array}{c}\text { 2-D } \\
\text { optical: } \\
3-\mathrm{D} \\
\text { thermal }\end{array}$} & 3rd pipe & 500 & 500.0191 & 0.158273 & 4182 & 12.662 \\
\hline & 4th pipe & 500 & 500.0208 & 0.158273 & 4182 & 13.774 \\
\hline & $\begin{array}{c}\text { total } \\
\text { (divergence } \\
\text { percentage) }\end{array}$ & & & & & $\begin{array}{c}26.436 \\
(-0.42 \%)\end{array}$ \\
\hline \multirow{3}{*}{$\begin{array}{c}\text { Full 3- } \\
\text { D }\end{array}$} & 3rd pipe & 500 & 500.0192 & 0.158027 & 4182 & 12.689 \\
\hline & 4th pipe & 500 & 500.021 & 0.157795 & 4182 & 13.858 \\
\hline & $\begin{array}{c}\text { total } \\
\text { (divergence } \\
\text { percentage) }\end{array}$ & & & & & $\begin{array}{c}26.547 \\
(0 \%)\end{array}$ \\
\hline
\end{tabular}


The geometry of the full 3-D domain and its mesh is displayed in Figure 15. For the comparison, the boundary conditions, material properties and CFD settings of the full 3-D domain and 3-D thermal domain are the same as previously discussed except for the air in the cavity being considered a solid and the glass having no absorption in Band 0. In addition, since the full 3-D model could not be run with the same mesh density and angular discretisations settings as the 2-D optical model discussed above because of computer memory limitations, a lower resolution 2-D optical result was used in the comparison. To allow for a direct comparison, the influence of mesh and angular discretisation (as illustrated in Figure 11) was therefore removed. In order to do this, the absorbed flux distribution obtained with the 2-D optical model was scaled to be the same as that obtained with the full 3-D model (see Figure 16 for the respective heat sources). The integrated results of the two methods are compared in Table 12. The results show a good agreement with the total amount of energy transferred to the HTF indicating a $0.4 \%$ difference. This fact proves the reliability of the much less expensive phased 2-D:3-D approach.

\subsection{Discussion of advantages and disadvantages of proposed approach}

A discussion of the advantages and disadvantages of the novel phased approach as compared with a full 3-D finite volume (optical and thermal) model method for a 2-D optical simulation and then a 3-D thermal cavity simulation will now be given.

The advantage of the full 3-D simulation using an FV approach is that the non-uniform solar heat flux is calculated directly without requiring conversion or interpolation. It is also easier to set up as the same CFD model is used to evaluate all the heat transfer mechanisms involved. Its main disadvantage is its increased cost both in terms of solution time and computer memory required. For instance, on the aforementioned machine (Intel with core ${ }^{\mathrm{TM}} \mathrm{i7}-3970 \mathrm{X}$ CPU and $32 \mathrm{~GB}$ RAM), the full 3-D model required more than 32 GB RAM beyond 3*50 DO discretisation while the 2-D:3-D approach required less than $12 \mathrm{~GB}$ for a 3*100 DO discretisation. From a computational run-time viewpoint, the full 3-D model was much more expensive since the RTE needed to be solved over $8 \times N_{\theta} \times N_{\phi}$ control angles, while in the 2-D optical model only $4 \times N_{\theta} \times N_{\phi}$ control angles were required (see Table 1). In addition, for the same cross-sectional mesh, the full 3-D had five times more mesh cells because of the third dimension further increasing the cost of the RTE solution. Although the Navier-Stokes and turbulence equations were only solved in the HTF domain, the energy equation had to be solved in the whole 3-D domain, which has five times more cells than the 2-D counterpart below the cavity. In the phased approach, the 3-D thermal model only required coarse control angles because of the dominance of diffuse re-radiation. In summary, for a comparison of run-time, the full 3-D model required at least 24 hours for its convergence while the phased approach converged after a few hours. This issue may not be crucial when a researcher just wants to run a few cases but it will be very important in an optimisation process that requires many simulations (e.g., 79 simulations were performed in Moghimi et al. $(2014,2015)$ to optimise an LFC cavity receiver). 


\section{Conclusions}

The following conclusions can be made from this study:

1) The solution of the radiative transfer equation using a Finite Volume (FV) CFD implementation of the discrete ordinates approach in ANSYS Fluent is accurate enough for solar applications as illustrated through the determination of the thermal performance of a Linear Fresnel Collector (LFC) cavity receiver and associated mirror field.

2) Through a sufficient mesh refinement and a careful selection of the angular discretisation settings or control angles, the errors of ray effect and false scattering can almost be eliminated.

3) Because of the 2-D nature of a line concentration LFC concentrated solar power plant, advantage can be taken of a 2-D FV optical simulation of the mirror field to determine the non-uniform absorbed radiation profile on the collector pipes in the cavity. If noon conditions are considered, the domain can be halved using symmetry.

4) In the paper, the accuracy of this 2-D FV simulation was evaluated and confirmed by performing a separate Monte Carlo ray-tracing simulation using SolTrace and obtaining excellent correlation.

5) The result of the 2-D optical simulation can be patched as a volumetric heat source in a 3-D conjugate heat transfer thermal model of the receiver cavity to determine the heat transferred to the Heat Transfer Fluid (HTF) as well as the thermal losses from the cavity.

6) This phased approach was validated by comparing it with a full 3-D CFD model of the mirror field and cavity with HTF. The energy transferred to the HTF compared to within $0.4 \%$.

7) The novel approach defined in this paper shows promise for implementation in optimisation studies where numerous simulations are run, which require an accurate evaluation of cavity heat loss contributions and heat transferred to the HTF, not to mention the effect of mirror field layout.

\section{Supplementary material}

\section{Section 1: RTE equation}

The RTE describes the balance of energy through the interaction of emission, absorption and scattering in a participating medium. Imagine a beam with a radiative intensity of $I_{\lambda}(\vec{r}, \vec{s})$, which is a function of the spectral variable $(\lambda)$, position $(\vec{r})$ and direction $(\vec{s})$, and which travels in an absorbing, scattering and emitting medium in the aforementioned direction. On the one hand, the beam energy decreases due to absorption and its scattering from its initial trajectory to other directions (out-scattering), while on the other hand, its energy increases due to medium volume thermal radiation emission and scattering from other trajectories towards its trajectory (inscattering). Mathematically, this is expressed as (Modest, 2013):

$$
\nabla .\left(I_{\lambda}(\vec{r} . \vec{s}) \vec{s}\right)+\beta_{\lambda} I_{\lambda}(\vec{r} . \vec{s})=a_{\lambda} n^{2} I_{b \lambda}+\frac{\sigma_{s, \lambda}}{4 \pi} \int_{0}^{4 \pi} I_{\lambda}\left(\vec{r} . \vec{s}^{\prime}\right) \phi\left(\vec{s} . \vec{s}^{\prime}\right) d \Omega^{\prime}
$$


$I_{\lambda}$ is the radiation intensity, $a_{\lambda}$ is the absorption coefficient, $\beta_{\lambda}=a_{\lambda}+\sigma_{s, \lambda}$ the combination of the absorption and scattering coefficients, and $\Omega$ ' the solid angle. The scattering coefficient $\sigma_{s}$, the scattering phase function $\phi$, and the refractive index $n$ are assumed to be independent of wavelength. The summation of all terms on the right-hand side is called the source term. Moreover, the difference between incident and outgoing intensity is defined as radiative flux which its definition for a non-grey medium is

$$
q_{R}(r)=\int_{0}^{\infty} \int_{0}^{4 \pi} I_{\lambda}(\vec{r} \cdot \vec{s}) \vec{s} d \Omega^{\prime} d \lambda
$$

The mentioned flux is the flux at physical boundaries of computational domain. However, for a calculating the net radiative energy withdraws from every each volume element a new term (The divergence of heat flux) is defined. This term is calculated by double integration of the RTE equation over all solid angles over all wavelengths, the divergence of heat flux can be calculated as

$$
\nabla \bullet q_{R}=\int_{0}^{\infty} a_{\lambda}\left(4 \pi I_{b \lambda}-\int_{0}^{4 \pi} I_{\lambda}\left(\vec{s}^{\prime}\right) d \Omega^{\prime}\right) d \lambda
$$

Equation (10) is incorporated as one of the heat transfer mechanisms in the energy conservation equation (equation (11)):

$$
\rho c_{v} \frac{D T}{D t}=\nabla \bullet(k \nabla T)-\nabla \bullet q_{R}-p(\nabla \bullet v)+\Phi+\dot{Q}^{\prime \prime \prime}
$$

The right-hand side of equation (11) contains the conductive heat flux, the radiative heat flux (provided by equation (10)), the pressure work term, the viscous dissipation function and finally additional heat sources that may be present. As implemented, the RTE equation is therefore coupled with the energy equation provided a direct link between the temperature field and the radiation intensity in a domain.

\section{Section2: Simulation in Soltrace}

Because of a lack of good documentation in defining the location and orientation of reflective and absorbing elements in SolTrace, the following description is described.

Consider the LFC layout in Figure 17, where each mirror element rotation angle (and hence each mirror normal vector) has to be set so that reflected rays impinge on a specific point (target point). This target point is different from the aim point in SolTrace. For the definition of the $\mathrm{N}$ elements' aiming points, an imaginary plane is defined in Figure 17 (see “Aiming Plane”). This plane is defined for the mirror elements and is normal to the cavity cross-section, which passes through the target point at a distance $H$ above the centre of the mirror field. The target vector $\vec{t}$ is defined from the centre of the $N_{t h}$ element to the target point in the cavity. The sun vector $\vec{s}$ is defined from the centre of the $N_{t h}$ mirror element to the sun position. 


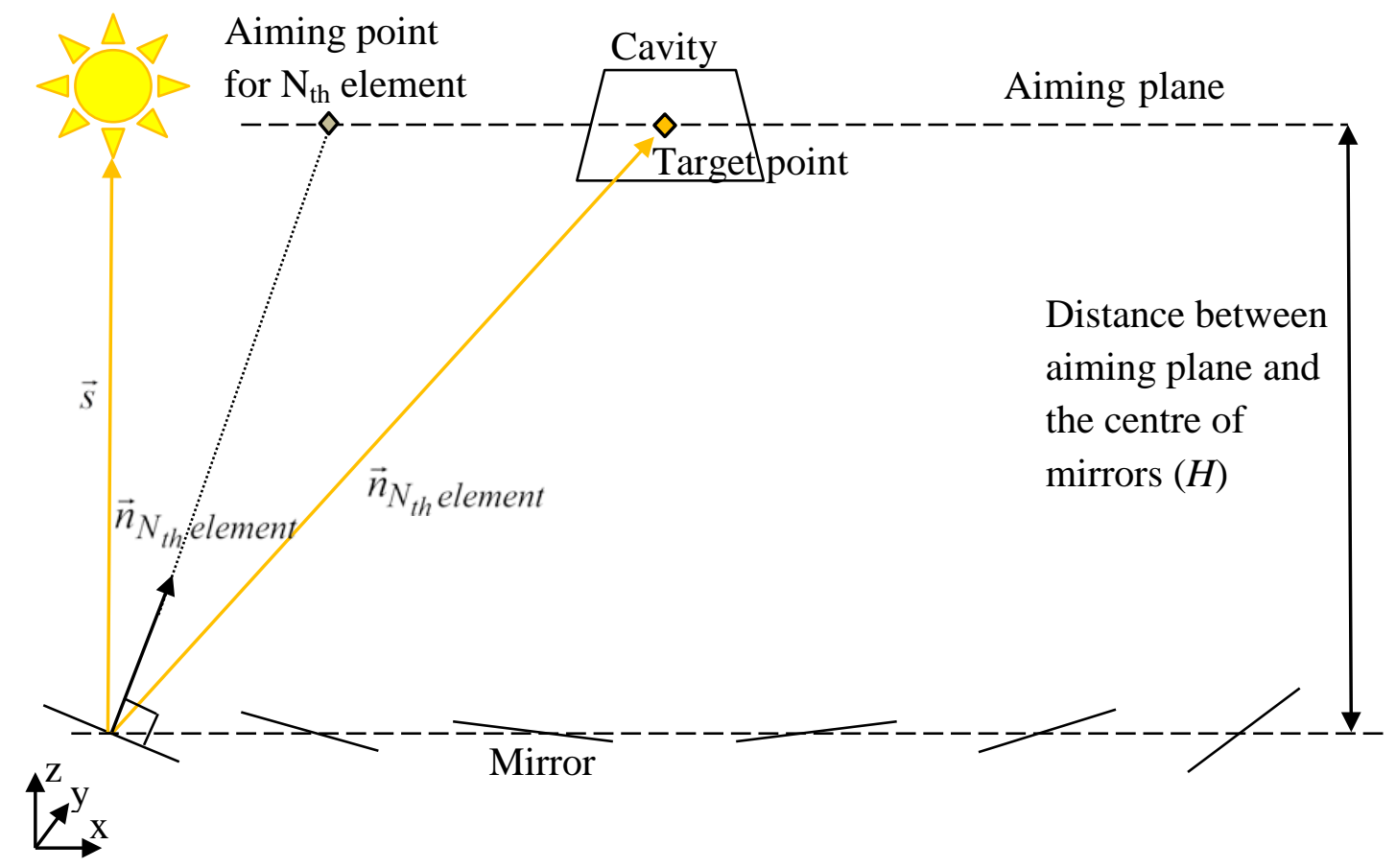

Figure 17: Schematic of LFC modelling in SolTrace 
So far, one target point, $N$ target vectors and $N$ sun vectors have been defined for modelling in SolTrace. However, when considered in the global coordinate system, the distance between the sun and the mirror field is many orders (11) of magnitude larger than the distance between adjacent mirrors and the target point, implying that the $N$ sun vectors can be reduced to only one vector. This sun vector is defined as the vector between the origin of global coordinate on the ground and the sun position. By assuming perfect reflection, the impinging ray on a surface has the same angle relative to the face normal as that between the face normal and the reflected ray, therefore the normal unit vector (Figure 17) is defined as:

$$
\hat{n}_{N_{\text {th }} \text { Element }}=\frac{\vec{s}+\vec{t}_{N_{t h} \text { Element }}}{\sqrt{|\vec{s}|^{2}+\left|\vec{t}_{N_{t h} \text { Element }}\right|^{2}+2\left(\vec{s} \cdot \vec{t}_{N_{t h} \text { Element }}\right)}}
$$

The SolTrace aim point of an element is the global coordinates of the intersection of its normal vector with the aiming plane, so:

$$
\begin{aligned}
& X_{\text {Aim Point for } N_{\text {th }} \text { Element }}=X \text { Centre of } N_{\text {th }} \text { Element } \\
& Y_{\text {Aim Point for } N_{\text {th }} \text { Element }}=Y \text { Centre of } N_{\text {th }} \text { Element } \\
& Z_{\text {Component }} \text { of } \hat{n}_{N_{\text {th }} \text { Element }}
\end{aligned}
$$

Using equation (13), the aim points are defined in SolTrace. These formulae are only valid for the mirror elements. For the other elements in the cavity enclosure (cavity walls and pipes), the aiming plane, the distance between the aiming plane and the centre of that element are not the same as those defined for the mirror elements.

\section{Section3: Patching the non-uniform heat flux of optical domain in 3-D thermal domain}

The following procedure (Craig et al., 2010) describes the patching of the non-uniform heat flux (taken from 2-D optical domain) on the absorber pipes of the 3-D thermal domain as a volumetric heat source:

1) Convert the absorbed radiation (solar load) on the pipes from the 2-D optical simulation into an interpolation file with the required 3-D Fluent format (*.ip). This process involves scaling the heat flux $\left[\mathrm{W} / \mathrm{m}^{2}\right] q^{\prime \prime}$ to a volumetric heat source $\left[\mathrm{W} / \mathrm{m}^{3}\right] Q$ by satisfying the formula:

$$
\begin{aligned}
& q^{\prime \prime} 2 \pi R L=Q \pi\left(R^{2}-r^{2}\right) L \\
& \therefore Q=q^{\prime \prime} \frac{2 \pi R L}{\pi\left(R^{2}-r^{2}\right) L}=q^{\prime \prime} \frac{2 R}{(R+r)(R-r)} \approx \frac{q^{\prime \prime}}{(R-r)} \text { for } 2 R \approx R+r
\end{aligned}
$$


with $L$ the pipe length, $R$ the outer and $r$ the inner radius of the shell. For a very thin shell, this reduces to division by the shell thickness as indicated.

2) Under Define/User-Defined, activate one scalar UDS-0 for all cell zones (fluid and solid) and one user-defined memory location (UDM-0).

3) Initialise case and data, or if the data exist, patch zero values to UDS-0 and UDM-0 for all cell zones.

4) In the File/Interpolate, interpolate each individual source file (*.ip file) to the UDS in each corresponding cell zone.

5) Define and interpret a UDF: DEFINE_ON_DEMAND (copy_UDS_to_UDM ) to copy the interpolated scalar data from UDS-0 to UDM-0.

6) Define and interpret a UDF: DEFINE_SOURCE that links a source name to the UDM.

7) Assign the source term of the appropriate name-selected solid cell zone to the UDF name in 6).

8) For saving memory during the ensuing simulation, the scalar "UDS-0" can be deactivated.

\section{Acknowledgements}

The authors would like to acknowledge the support of the University of Pretoria (South Africa) and the South African National Research Foundation (DST-NRF Solar Spoke).

\section{References}

ANSYS, 2006. Fluent UDF manual, version 6.3, ANSYS Incorporated. ANSYS, 2013a. Design Exploration User Guide, version 15, ANSYS Incorporated. ANSYS, 2013b. Fluent Theory manual, version 15, ANSYS Incorporated. ANSYS, 2013c. ANSYS Workbench manual, version 15, ANSYS Incorporated.

Bergman, T.L., Lavine, A.S., Incropera, F.P., Dewitt, D.P., 2011. Fundamentals of heat and mass transfer, 7th edition, John Wiley and Sons.

Bernhard, R., Laabs, H.-G., De Lalaing, J., Eck, M., Eickhoff, M., Pottler, K., Morin, G., Heimsath, A., Georg, A., Häberle, A., 2008. Linear Fresnel Collector demonstration on the PSA Part 1 - Design, construction and quality control, 14th International Symposium on Concentrated Solar Power and Chemical Energy Technologies, SolarPACES 2008, Las Vegas, USA.

Bode, S.J., Gauché, P., 2012. Review of optical software for use in Concentrated Solar Power systems. SASEC 2012, 21-23 May, 2012, Stellenbosch, South Africa.

Brunner, T.A., 2000. Riemann solvers for time-dependent transport based on the maximum entropy and spherical harmonics closures. Ph.D. thesis, University of Michigan.

Brunner, T.A., 2002. Forms of approximate radiation transport, SANDIA Report, SAND20021778.

Chai, J.C., Lee, H.S., Patankar, S.V., 1993. Ray e1ect and false scattering in the discrete ordinates method. Numer Heat Tr Part B 24, 373-389. 
Chai, J.C., Patankar, S.V., 2006. Discrete-ordinates and finite-volume methods for radiative heat transfer, chapter in Handbook of Numerical Heat Transfer, 2nd edition, John Wiley \& Sons.

Cheng, Z.D., He, Y.L., Cui, F.Q., Xu, R.J., Tao, Y.B., 2012. Numerical simulation of a parabolic trough solar collector with nonuniform solar flux conditions by coupling FVM and MCRT method, Solar Energy, 86, 1770-1784.

Craig, K.J., Harkness, A.W., Kritzinger, H.P. \& Hoffmann, J.E., 2010. Analysis of AP1000 reactor vessel cavity and support cooling, Paper ECN2010-A0459, European Nuclear Conference (ENC2010), 30 May - 2 June 2010, Barcelona, Spain.

Facão, J., Oliveira, A.C., 2011. Numerical simulation of a trapezoidal cavity receiver for a linear Fresnel solar collector concentrator, Renewable Energy, 36, 90-96.

Fleck, J.A. Jr., Cummings, J.D., 1971. An implicit Monte Carlo scheme for calculating time and frequency dependent nonlinear radiation transport, Journal of Computational Physics, 8, 313342.

Ghadirijafarbeigloo, Sh., Zamzamian, A.H., Yaghoubi, M., 2014. 3-D numerical simulation of heat transfer and turbulent flow in a receiver tube of solar parabolic trough concentrator with louvered twisted-tape inserts, Energy Procedia, 49, 373 - 380.

He, Y.L., Xiao, J., Cheng, Z.D., Tao, Y.B., 2011. A MCRT and FVM coupled simulation method for energy conversion process in parabolic trough solar collector, Renewable Energy, 36, 976-985.

Hachicha, A.A., 2013. Numerical modelling of a parabolic trough solar collector, Ph.D. Thesis, Universitat Politècnica de Catalunya.

Incropera, F., Dewitt, D., 1990. Fundamentals of heat and mass transfer. 3rd edition, New York: John Wiley and Sons.

Jessee J.P., Fiveland W.A., 1997. Bounded, high resolution differencing schemes applied to the discrete ordinates method, J Thermophys Heat Tr, 11, 540-548.

Joseph, D., Perez, P., Hafi, M.E., Cuenot, B., 2009. Discrete ordinates and Monte Carlo methods for radiative transfer simulation applied to computational fluid dynamics combustion modelling, ASME J Heat Tr, 131, 052701.

Kim, T., Lee, H.S., 1989. Radiative transfer in two-dimensional anisotropic scattering media with collimated incidence, J. Quant. Spectrosc. Radiat. Transfer, 42, 225-238.

Kennedy, C.E., 2002. Review of mid- to high-temperature solar selective absorber materials, National Renewable Energy Laboratory, NREL/TP-520-31267, July 2002.

Levermore, C.D., Pomraning, G.C., 1981. A flux-limited diffusion theory, The Astrophysical Journal, 248, 321.334.

Li, H., 2004. Reduction of false scattering in arbitrarily specified discrete directions of the discrete ordinates method, J. Quant. Spectrosc. Radiat. Transfer, 86, 215-222.

Li, H.S., Flamant, G., Lu, J.D., 2002. Reduction of false scattering of the discrete ordinates method. ASME J. Heat Tr, 124, 837-844.

Lin, M., Sumathy, K., Dai, Y.J., Wang, R.Z., Chen, Y, 2013. Experimental and theoretical analysis on a linear Fresnel reflector solar collector prototype with V-shaped cavity receiver, Applied Thermal Engineering, 51, 963-972. 
Martinek. J., Weimer, A.W., 2013. Evaluation of finite volume solutions for radiative heat transfer in a closed cavity solar receiver for high temperature solar thermal processes, Int. J. Heat Mass Transfer, 58, 585-596.

Mertins, M., 2009. Technische und wirtschaftliche Analyse von horizontalen FresnelKollektoren, Ph.D. thesis, Universität Karlsruhe.

Miller, W.F., Reed, W.H., 1977. Ray-effect mitigation methods for two-dimensional neutron transport theory. Nuclear Science and Engineering, 62, 391-411.

Minerbo, G.N., 1978. Maximum entropy Eddington factors, J. Quant. Spectrosc. Radiat. Transfer, 20, 541-545.

Modest, M.F., 2013. Radiative Heat Transfer, 3rd edition, Elsevier.

Moghimi, M.A., Craig K.J., Meyer, J.P., 2014. Response surface method optimization of cavity absorber of a Linear Fresnel Reflector, SASEC 2014, 27-29 January, 2014, Port Elizabeth, South Africa.

Moghimi, M.A., Craig K.J., Meyer, J.P., 2015. Optimization of a trapezoidal cavity absorber for the Linear Fresnel Reflector, Solar Energy, Under revision.

Montes, M.J., Abbas, R., Rovira, A., Martínez-Val, J.M., Muñoz-Antón, J., 2012. Analysis of Linear Fresnel Collector designs to minimize optical and geometrical losses, SolarPACES 2012, Marrakesh, Morocco.

Morin, G., Platzer, W., Eck, M., Uhlig, R., Häberle, A., Berger, M., and Zarza, E., 2006. Road map towards the demonstration of a Linear Fresnel Collector using a single tube receiver, 13th International Symposium on Concentrated Solar Power and Chemical Energy Technologies, SolarPACES 2006, Seville, Spain.

NREL, 2014. SolTrace Optical Modeling Software, http://www.nrel.gov/csp/soltrace, Last accessed: 2.12.2014.

Pye, J.D., 2008. System Modelling of the Compact Linear Fresnel Reflector, Ph.D. Thesis, University of New South Wales, Australia.

Raithby, G.D., Chui, E.H., 1990. A finite-volume method for predicting a radiant heat transfer in enclosures with participating media, J. Heat Transfer, 112, 415-423.

Ramankutty, M.A., Crosbie, A.L., 1998. Modified discrete-ordinates solution of radiative transfer in three-dimensional rectangular enclosures, J. Quant. Spectrosc. Radiat. Transfer, 60, 103-134.

Schlichting, H., 1979. Boundary-Layer Theory, 7th Edition, McGraw-Hill Book Company, New York.

TIASA, 2001. Thermal Insulation Handbook, Thermal Insulation Association of Southern Africa.

White, F.M., 2006. Viscous Fluid Flow, 3rd Edition, McGraw Hill.

Wirz, M., Petit, J., Haselbacher, A., Steinfeld, A., 2014. Potential improvments in the optical and thermal efficiencies of parabolic trough concentrators, Solar Energy, 107, 398-414. 